\title{
Geophysical methods to assess soil characteristics
}

\author{
Ho-Chul Shin ${ }^{1}$, Guillaume Blanchy ${ }^{2}$, lan Shield ${ }^{1}$, Peter Fruen ${ }^{1}$, Timothy Barraclough ${ }^{1}$, Christopher W. \\ Watts ${ }^{1}$, Andrew Binley ${ }^{2}$ and William R. Whalley ${ }^{1}$ \\ ${ }^{1}$ Rothamsted Research, Harpenden, Hertfordshire AL5 2JQ, UK \\ ${ }^{2}$ Lancaster University, Lancaster, Lancashire LA1 4YQ, UK
}

\author{
1. Introduction \\ 2. Geophysical properties of soil \\ 3. Electromagnetic Induction \\ 3.1 Applications of EMI \\ 4. Electrical resistivity \\ 4.1 Applications of electrical resistivity \\ 5. Acoustic-to-seismic coupling \\ 5.1 Model for acoustic-to-seismic coupling \\ 5.2 Applications of acoustic-to-seismic coupling model \\ 5.3 Deducing the soil water contents by wave-speed measurements \\ 6. Summary \\ 7. Acknowledgments \\ References
}

\section{Introduction}

In this chapter we explore the use of geophysical methods to assess soil physical characteristics. Several geophysical methods can be used for this purpose, such as electrical resistivity, induced polarisation, electromagnetic induction methods, ground penetrating radar, nuclear magnetic resonance as well as methods based on seismic wave analysis (Table 1). Most geophysical methods do not directly measure soil characteristics but rather physical properties that may be related to properties or states of interest. Relationships to convert the physical property measured to the soil characteristics of interest play an essential role in using geophysical tools for soil science. It is also important to note that different soil characteristics can affect the same physical property, which complicates the interpretation of the geophysical results. For instance, soil moisture and salinity can both increase the soil electrical conductivity. Different methodological strategies can be used to separate these multiple effects.

With the exception of ground penetrating radar, geophysical methods used in soil studies originate from mineral and oil exploration. The scalability of the methods has allowed application to shallow investigation of the subsurface. Growth in their use in hydrology expanded in the 1990s (e.g. Binley et al., 2015) and, more recently, has been widely integrated in many agronomy investigations (e.g. Allred et al., 2008). Static surveys (i.e. conducted at one point in time) can be effective for mapping variation of soil properties; the adoption of time-lapse surveys can help reveal changes to states (e.g. soil moisture) or properties (e.g. density) over time (e.g. Blanchy et al., 2020a).

Electrical resistivity methods measure the subsurface electrical resistivity distribution using an array of electrodes, typically on the ground surface. Such methods can be used for mapping spatial patterns of electrical resistivity using mobile arrays but are commonly used with a fixed array of electrodes to determine a 2D (vertical section) or 3D image of the subsurface (Binley, 2015; Binley and Slater, 2020). The term electrical resistivity tomography (ERT) is commonly used in reference to 
imaging with a fixed array of electrodes. Samouëlian et al. (2005) provides an introduction to ERT for soil studies, while the recent review of Cimpoiaşu et al. (2020) describes the application of geoelectrical methods for root studies. Electromagnetic induction (EMI) relies on the measurement of the electromagnetic field from induced eddy currents to infer the subsurface electrical conductivity (the conductivity is the inverse of the resistivity). As a contactless method, it is widely used for mapping large areas. Doolittle and Brevik (2014), Sudduth et al. (2005) and Corwin et al. (2006), amongst others, demonstrate the use of EMI for soil studies.

Electrical resistivity (or conductivity) methods can sometimes result in ambiguous interpretation because of the number of factors that can change the resistivity of a soil. Induced polarisation (Binley and Slater, 2020) is an extension of the resistivity method that is sensitive to the storage of electrical charge, and consequently senses electrical characteristics of the soil grain surface, making it effective at differentiating variation in resistivity due to both pore water ionic content and clay content (Slater and Lesmes, 2002). The direct link between induced polarisation and grain surface characteristics has prompted a number of studies using induced polarisation to infer permeability of Earth materials (e.g. Weller et al., 2015).

Ground penetrating radar (GPR) sends radar pulses into the ground and records their multiple 'echos' to build an image of the subsurface revealing material with contrasting electrical permittivity. This can be extremely effective at mapping lithological boundaries or soil horizons. The speed of the radar wave is directly related to soil water content (as is exploited in the commonly used dielectric methods for soil moisture) and thus knowledge of the radar velocity allows the assessment of soil moisture. Analysis of radar velocity (and hence soil moisture) can be carried out at shallow depths using reflected signals or the direct wave that travels along the ground surface (e.g., Algeo et al., 2018). Like GPR, nuclear magnetic resonance (NMR), is also sensitive to water content in soils (Paetzold et al., 1985). In saturated soils NMR signals can be used to infer a pore size distribution and permeability. The method is based on the interaction of hydrogen nuclei moments and an externally applied magnetic field. Most applications of NMR have focussed on relative deep investigations (up to hundreds of metres), although recent advances in instruments are permitting very shallow depths of investigation, opening up opportunities for soil studies.

Seismic waves methods, with which acoustic methods are related, rely on the analysis of the 'echos' of elastic waves through the soil. Seismic methods share some similarity with GPR which relies on an electromagnetic pulse. While geophysical methods were initially used to characterise lithological features, often to depths of hundreds of metres such as for mineral exploration, their use in agriculture is focused on shallow layers, usually to the depth of crop roots (a few metres). Their minimal invasiveness and high-throughput offer great potential for non-destructive study of the soil characteristics for agriculture.

It is not possible to cover all these methods and approaches in a single chapter, instead we focus on three methods, which have specific values for soil investigations. For a more exhaustive overview of the different geophysical methods for agriculture, we redirect the reader to Allred et al. (2008). The first two methods we cover are electromagnetic induction and electrical resistivity, which are well established in agriculture. The third method is an emerging method based on acoustic to seismic coupling. The first two methods have been used in agriculture and soil science for both mapping soil characteristics, such as salinity and clay content, and for more detailed studies of soil processes, often related to water and solute movement (Beff et al., 2013; Binley et al., 1996; Blanchy et al., 2020b; Dahlin et al., 2014; Koestel et al., 2008; Reyes, et al., 2018; Shanahan et al., 2015; Whalley et al., 2017). Methods based on the analysis of seismic waves are sensitive to the elastic properties of soil but also depend on soil water status and soil compaction. 
Table 1 A summary of the different geophysical methods for soil probing and their associated geophysical properties and soil characteristics that can be derived.

\begin{tabular}{|l|l|l|}
\hline Method & $\begin{array}{l}\text { Basic physical property } \\
\text { affecting measurement }\end{array}$ & Soil characteristics \\
\hline Electrical resistivity & Electrical resistivity & $\begin{array}{l}\text { Saturation, porosity, } \\
\text { clay content, ionic } \\
\text { concentration of pore } \\
\text { water, salinity }\end{array}$ \\
\hline Induced polarisation & Chargeability & $\begin{array}{l}\text { Clay content, grain } \\
\text { surface area }\end{array}$ \\
\hline $\begin{array}{l}\text { Electromagnetic } \\
\text { induction }\end{array}$ & Electrical conductivity & $\begin{array}{l}\text { Saturation, porosity, } \\
\text { clay content, ionic } \\
\text { concentration of pore } \\
\text { water, salinity }\end{array}$ \\
\hline $\begin{array}{l}\text { Ground penetrating } \\
\text { radar }\end{array}$ & Electrical permittivity & $\begin{array}{l}\text { Soil horizon boundaries, } \\
\text { saturation }\end{array}$ \\
\hline $\begin{array}{l}\text { Nuclear Magnetic } \\
\text { Resonance }\end{array}$ & $\begin{array}{l}\text { Resonant properties of } \\
\text { hydrogen nuclei }\end{array}$ & $\begin{array}{l}\text { Saturation and pore size } \\
\text { (in saturated soils) }\end{array}$ \\
\hline Seismic method & Elastic properties & $\begin{array}{l}\text { Soil strength and } \\
\text { internal stress }\end{array}$ \\
\hline
\end{tabular}

\section{Geophysical properties of soil}

In practice geoelectrical methods such as EMI and ERT are sensitive to a number of properties that are reasonably constant (clay content, organic matter content) as well as ephemeral states such as soil temperature, pore water electrical conductivity, bulk density and volumetric soil water content. The soil structure affects electrical conductivity by virtue of pore connectivity and porosity.

Archie's law (Archie, 1942), originally developed for oil reservoir investigations, is a commonly used empirically derived model that relates the soil condition to the bulk electrical conductivity. In terms of resistivity, Archie's law may be expressed, for fluid saturated porous media, by $\rho_{o}=\rho_{\mathrm{w}} \Phi^{-m}$ with the resistivity of saturated media $\left(\rho_{o}\right)$, the resistivity of pore fluid $\left(\rho_{\mathrm{w}}\right)$, the porosity $(\Phi)$ and the exponent $(m)$. The resistivity of partly-saturated media $(\rho)$ can be expressed as $\rho=\rho_{0} S^{-n}$ with the saturation $(S)$ and exponent $(n)$. Waxman and Smits (1968) extended Archie's law by accounting for the effect of clay minerals (forming surface electrical conductivity). Several other approaches have been developed specifically for soils (e.g., Rhoades et al., 1976). Laloy et al. (2011) compared a range of models for soil electrical conductivity, adopting the term "pedo-electrical" model to differentiate this from classical petrophysical approaches.

The electrical resistivity (respectively, conductivity) is a measure of how difficult (respectively, easy) an electrical current can flow through and is a property of the material independent of its dimension. The resistivity and conductivity are reciprocally related. Their MKS units are ohm metre $(\Omega \mathrm{m})$ and siemens per metre $(\mathrm{S} / \mathrm{m})$, respectively. A textbook introduction to the electrical resistivity and conductivity often refers to a direct current flow through a finite-length $(L)$ rod with a uniform cross-section $(A)$. Then, resistivity $(\rho)$ and conductivity $(\sigma)$ are defined as $\sigma=R A / L$ and $\sigma=G L / A$ where $R=V / I=1 / G$; then, $R, G, V$ and $I$ are the resistance, conductance, voltage difference and current, respectively. When an alternating current with varying frequency is employed instead of a direct current, the electrical property can also be a function of frequency. However, for materials with conductivity in the range $(1-1000 \mathrm{mS} / \mathrm{m})$ usually measured by most electromagnetic induction 
devices, the electrical properties are largely independent of frequency. Therefore, the electrical conductivity measured by an electromagnetic induction equipment operating in low-frequency and low induction number is likely the same as the inverse of the electrical resistivity measured by a direct-current resistivity method (McNeill, 1980a).

Soils are the result of various weathering processes acting on parent materials whose physical and chemical properties are altered consequently. Structurally, soils are made up with mineral matrix and interwoven voids (or pores). Most soil minerals are effectively electrical insulators with negligible electrical conductivity, except some rare exceptions. Therefore, soil electrical conductivity is usually associated with the pores having the moisture in various stages of saturation. Soil electrical conductivity is electrolytic in nature and hence is affected by the number and mobility of ions. The ease of movement of the ions is largely determined by the fluid viscosity. The viscosity of fluid depends on the temperature of the fluid. Therefore, the electrical conductivity is also affected by the temperature (McNeill, 1980a).

The relation between the electrical conductivity and temperature is generally nonlinear. However, over normal ambient temperatures, the degree of nonlinearity is relatively small, a linear equation known as the ratio model is commonly used (McNeill, 1980a):

$$
\sigma(T)=\sigma(25)[1+a(T-25)],
$$

where $\sigma(T)$ is the electrical conductivity measured at a temperature $T\left({ }^{\circ} \mathrm{C}\right)$ and $\sigma(25)$ is a reference electrical conductivity at a common temperature of $25^{\circ} \mathrm{C}$. The level of change is determined by a temperature compensation factor $a$. Several different choices have been used for $a$. McNeill (1980a) used $a$ from a sodium chloride solution $\left(a=0.022^{\circ} \mathrm{C}^{-1}\right)$ : i.e. $2.2 \%$ change per degree Celsius. Other values are $a=0.0191^{\circ} \mathrm{C}^{-1}$ based on $0.01 \mathrm{M} \mathrm{KCL}$ solution; $a=0.025^{\circ} \mathrm{C}^{-1}$ commonly used by geophysicists; $a=0.02^{\circ} \mathrm{C}^{-1}$ for " $2 \%$ increase of electrical conductivity per $1^{\circ} \mathrm{C}$ increase of temperature" frequently cited (Hayashi, 2004). Ma et al. (2011) offer a comparison of the different temperature correction available.

Temperature effects can be accounted for given local vertical soil temperature profiles, which can be assumed to have limited spatial variability within a site, although effects of daily or seasonal variation in temperature do need to be considered. The electrical conductivity of the pore water contributes significantly to the bulk conductivity of soil. In temperate climates, the variation of the pore water electrical conductivity should be minimal in rain-fed settings, but it may be greatly affected by irrigation depending on the source of the irrigation water (e.g. groundwater sourced). In semi-arid environments, pore water conductivity effects may be significant due to enhanced salinity arising from high evaporative fluxes (Corwin and Lesch, 2005).

Soils can also be examined by using elastic waves which require a medium (or a matter) to propagate through: sounds (or acoustic waves) are also part of elastic waves. In this regard, soils are the media whose particles are disturbed while the elastic waves are propagated. The elasticity inherent in soils act as a restoring force.

The soil as a wave-propagating medium, for elastic waves, can be approximated as either purely solid or porous media. For solid elastic media without constituent pores, there are two types of elastic waves which are well-known primary (P)-wave and secondary (S)-wave, also known as shear wave. The P-wave is a compressional (or longitudinal) wave in that the movement of particles are in the direction of wave propagation. The S-wave is a transverse (or shear) wave in that the disturbed particles oscillate perpendicular to the direction of waves. As the names suggest, P-wave propagates faster than S-wave. These are body waves which means that the medium of interest is unbounded. When a boundary or surface is considered, in addition to body waves, so-called surface waves are encountered such as Rayleigh waves, Love waves, etc. 
When the wave-propagating medium is porous, more waves can be present. If the pore network of a poroelastic (porous and elastic) medium is filled with a single fluid, e.g., either air-saturated or water-saturated, then we have three waves in total: two compressional waves and a shear wave. The phenomenon can be modelled by a two-phase poroelasticity theory pioneered by Biot (1956a, 1956b). If the pores are occupied by two different fluids such as unsaturated soils, four distinct waves are encountered: three compressional waves and a shear wave, when there is a wave path through water in addition to those through the solid and air (Arora and Tomar, 2008; Lo and Sposito, 2013). Theoretically, the aforementioned poroelasticity models assume the solid phase represented by a single material. In practice, the solid part is likely to be composed of different materials. However, the wavelength considered in these models are much larger than the inhomogeneity; therefore, different solid constituents can be treated as a single 'effective' material which represents the overall properties of various solid elements.

In the case of both geoelectrical and seismic probing of soil the first challenge is to determine the basic physical property of soil. The second challenge is to interpret that basic physical property in terms of some soil property of interest (see Table 1). For example, Reyes et al. (2018) employed the geostatistical interpolation such as ordinary kriging and cokriging with the electrical conductivity data to identify the spatial variability of soil clay content at the field scale. A laboratory work by Gao et al. (2013) demonstrated a relationship to calibrate the soil penetration resistance (i.e., soil strength) and the shear modulus (i.e., elastic property); their relationship was later adopted by Shin et al. (2017) to predict the penetration resistance from the shear modulus deduced by acoustic to seismic method.

\section{Electromagnetic Induction}

The electromagnetic induction (EMI) method is a non-invasive, high-throughput conductivity survey methods that can be done over large area with minimal setup (McNeill, 1980b). Modern equipment can also be mounted on a mobile platform such as a non-conducting sled (Corwin and Lesch, 2005), therefore enabling more efficient survey of large areas. Also in soil with higher clay content, cracks can appear around the electrodes for the resistivity method (discussed in section 4), resulting in poor galvanic contact; EMI does not suffer from this limitation (Sheets and Hendrickx, 1995). However, as EMI instruments are sensitive to electrical conductors, the method can be limited in very resistive environments (e.g. very dry clay-free soils). Note that what we refer to as EMI is more precisely frequency domain electromagnetic induction (also abbreviated FDEM). Time-domain electromagnetic methods (TEM) are out of the scope of this chapter as they are much less frequently used for agricultural applications.

EMI instruments are composed of at least two coils. One transmitter coil (Tx) and one receiver coil (Rx). The time-varying magnetic field arising from the alternating current in the transmitting coil at a certain frequency $\left(H_{p}\right)$ induces very small currents (eddy currents) in the ground. These currents generate a secondary magnetic field $H_{s}$ which is sensed, together with the primary field $H_{p}$, by the receiving coil (McNeill, 1980b). Stronger eddy currents will be induced in more conductive soil resulting in a larger secondary magnetic field. From the ratio between the primary and the secondary magnetic field, a value of the ground electrical conductivity can be obtained. This value is called 'apparent' electrical conductivity (often abbreviated ECa). Its apparent nature is derived from the fact that it represents a weighted average of the depth-specific electrical conductivity. The ECa represents the electrical conductivity of a homogeneous ground that would yield the signal measured by the EMI instrument. 
Different coil configurations of the Tx and Rx coils are used. When the plane of both Tx and Rx coils is vertical to the surface of the ground, the direction of dipoles is horizontal: this configuration is known as the horizontal dipole mode $(\mathrm{H})$ or the vertical co-planar mode (VCP). The other is the vertical dipole mode $(\mathrm{V})$, also called the horizontal co-planar mode (HCP), where the plane of the coils is horizontal. Both configurations can be achieved by a single instrument by simply rotating it ninety degrees. Additionally, the plane of the Tx and Rx coil can be perpendicular to each other: this is called the perpendicular orientation (PRP). In this section we focus on the vertical and the horizontal dipole modes only, because these are more commonly available commercially and both modes can be exploited by a single instrument.

The orientation and the distance between the Tx and Rx coil define the shape of the electromagnetic fields and hence the depth and the volume investigated by the EMI device. Larger coil separation between $T x$ and $R x$ results in a greater volume investigated. While original instruments had only one Tx and one Rx coil (such as the Geonics EM38 and EM35), more recent instruments (e.g. the GF Instruments CMD Mini-Explorer shown in Figure 3.1) are multi-coil, meaning they incorporate multiple $R x$ coils and one Tx coil. This enables the simultaneous measurement from multiple Tx-Rx coil separations and hence different depths of investigation at one time.

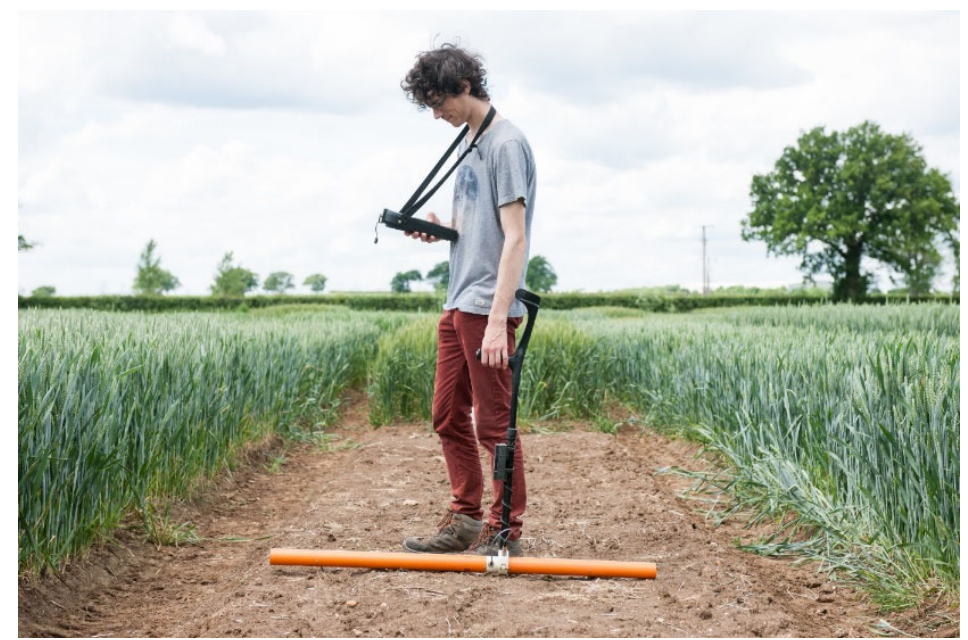

Figure 3.1 Operator using a CMD Mini-Explorer (GF Instruments, Brno, Czech Republic) to survey a wheat field.

Analytical expression of the ratios of the secondary field to the primary magnetic field for a homogeneous subsurface can be derived from Maxwell's equation and are given by (McNeill, 1980b):

$$
\left(\frac{H_{s}}{H_{p}}\right)_{V}=\frac{2}{(\gamma s)^{2}}\left[9-\left\{9+9 \gamma s+4(\gamma s)^{2}+(\gamma s)^{3}\right\} e^{-\gamma s}\right],
$$

for a vertical dipole mode, and

$$
\left(\frac{H_{s}}{H_{p}}\right)_{H}=2\left[1-\frac{3}{(\gamma s)^{2}}+\left\{3+3 \gamma s+(\gamma s)^{2}\right\} \frac{e^{-\gamma s}}{(\gamma s)^{2}}\right],
$$

for a horizontal dipole mode. $\gamma=\sqrt{i \omega \mu_{0} \sigma}$ with $\mu_{0}$ the free-space magnetic permeability, $\omega$ the angular frequency and $i$ the imaginary unit. Use of $\mu_{0}$ instead of $\mu$ (the magnetic permeability of the soil) means that we are largely concerned with non-magnetic environment.

The variable $\gamma$ can be represented by the electrical skin depth $\delta$ with the relationship $\gamma \delta=\sqrt{2 i}$. The skin depth is defined as the distance of travel at which an electromagnetic wave is attenuated by $1 / e \cong 0.368$. The ratio of the coil spacing $s$ (i.e. transmitter-receiver separation) to the skin depth $\delta$ is known as the induction number $B$ : i.e. $B=s / \delta$. Then, the combined variable $\gamma s$ can be expressed by $\gamma s=B \sqrt{2 i}$. Therefore, a low induction number $(B \ll 1)$, which is a common requirement for 
most commercial electromagnetic induction devices, is a condition where the coil spacing is much shorter than the skin depth and hence an important indicator of wave attenuation. A very conductive environment will increase the value of $\gamma$, decrease the skin depth $\delta$ and increase the induction number $\mathrm{B}$, potentially breaking the low induction number condition.

Under the low induction number condition, the imaginary part (i.e. quadrature) of the ratios of $H_{s}$ to $H_{p}$ can be simplified to

$$
\left(\frac{H_{S}}{H_{p}}\right)_{V} \cong\left(\frac{H_{s}}{H_{p}}\right)_{H} \cong \frac{(\gamma s)^{2}}{4}=\frac{i B^{2}}{2}=\frac{i \omega \mu_{0} \sigma s^{2}}{4},
$$

for both dipole orientations, by the Taylor series expansion of $e^{-\gamma s}$ with at least 5 terms. Therefore, at low values of induction number, the secondary magnetic field is a very simple function of $\omega, \sigma$ and $s$. When the operating frequency and coil spacings are arranged to ensure the low induction number for the range of conductivity of interest, the apparent electric conductivity $\sigma_{a}$ (also denoted by ECa) can be determined by using the imaginary part of the ratio of $H_{s}$ to $H_{p}$ :

$$
\sigma_{a}=\frac{4}{\omega \mu_{o} s^{2}} \operatorname{Im}\left(\frac{H_{s}}{H_{p}}\right)
$$

The condition of a low induction number ensures not only the aforementioned simple relationship to deduce the apparent conductivity, but also negligible magnetic coupling between the current loops. In addition, regardless of the value of the induction number, all current flows are assumed to be horizontal. In a horizontally layered soil (which is often assumed theoretically), the effect of the refraction of the current flows are assumed negligible, rendering further theoretical development more accessible. Therefore, the secondary magnetic field measured at the surface of a horizontally layered ground can be considered as the sum of all the contributions from each layer.

Under the condition of a low induction number $(B \ll 1)$, the relative sensitivity of the vertical $\left(S_{V}\right)$ and horizontal $\left(S_{H}\right)$ dipole configurations to layers at various depths is known as (McNeill, 1980b)

$$
\begin{gathered}
S_{V}(z)=4 z\left(4 z^{2}+1\right)^{-3 / 2} \\
S_{H}(z)=2-4 z\left(4 z^{2}+1\right)^{-1 / 2}
\end{gathered}
$$

where $z$ is a normalised depth: i.e. a depth divided by the coil spacing $s$. Therefore, $s$ and the coil orientation are the sole factor affecting the relative sensitivity distribution with depth. Note that $S_{H}(z)$ peaks at the surface $(z=0)$ : i.e. $S_{H}(0)=2$, then gradually decreases (Figure 3.2a). By contrast, $S_{V}(z)$ vanishes at the surface $\left(S_{V}(0)=0\right)$, peaks at $z=1 / \sqrt{8}$, i.e. $S_{V}(1 / \sqrt{8})=4 \sqrt{3} / 9$, then gradually decreases (Figure $3.2 \mathrm{a}$ ).

More useful may be its cumulative sensitivity function $\left(C S_{V}, C S_{H}\right)$ which accumulates the relative contribution to the secondary magnetic field from all layers below a given depth $z$ :

$$
\begin{gathered}
C S_{V}(z)=\int_{z}^{\infty} S_{V}(z) d z=\left(4 z^{2}+1\right)^{-1 / 2} \\
C S_{H}(z)=\int_{z}^{\infty} S_{H}(z) d z=\left(4 z^{2}+1\right)^{1 / 2}-2 z
\end{gathered}
$$

which means all the layers below a depth of $z$-times coil spacings produce a relative contribution of $C S_{V}(z)$ or $C S_{H}(z)$ to the indicated meter reading of the apparent conductivity. At the surface, the complete contribution is made from all the depths; therefore, $C S_{V}(0)=C S_{H}(0)=1$ (Figure 3.2b). For cases when the EMI instrument is not operated on the ground, a rescaled version of the CS function can be used (Andrade and Fischer, 2018). 

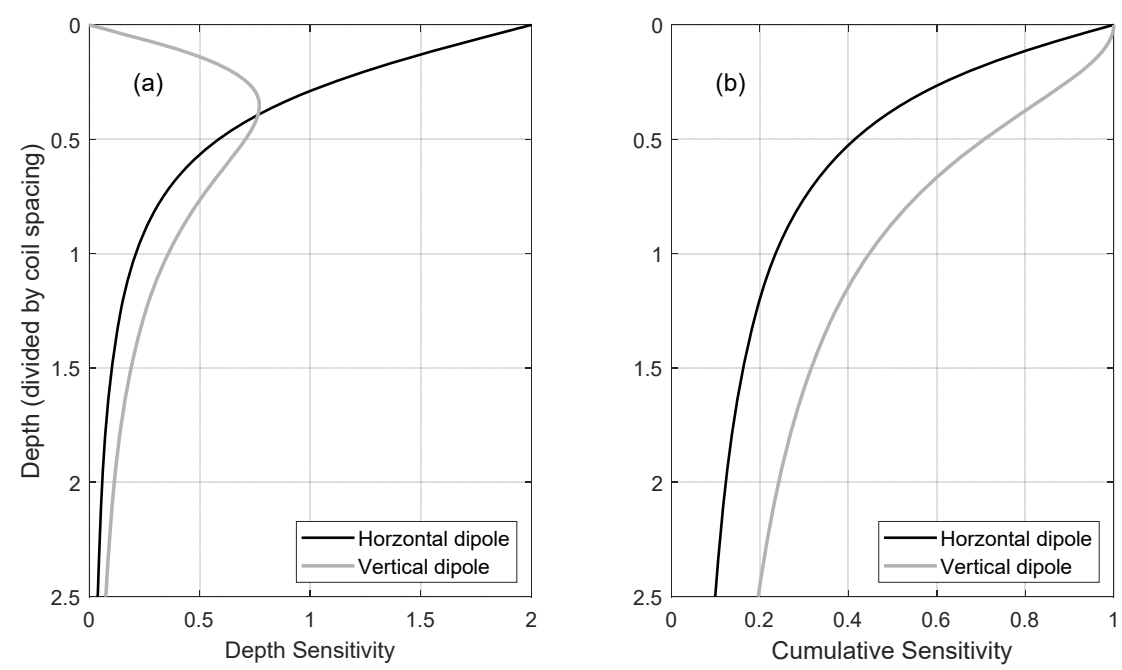

Figure 3.2. (a) relative sensitivity and (b) cumulative sensitivity of horizontal dipole and vertical dipole.

The apparent conductivity $\left(\sigma_{a}\right)$ from an electromagnetic induction meter on a horizontally layered earth model can be simply calculated by using the cumulative sensitivity functions, i.e., by adding up the contribution from each layer independently (e.g., JafarGandomi and Binley, 2013):

$$
\begin{aligned}
& \sigma_{a}=\sigma_{1}\left(1-C S\left(z_{1}\right)\right)+\sum_{j=2}^{N-1} \sigma_{j}\left(C S\left(z_{j-1}\right)-C S\left(z_{j}\right)\right)+\sigma_{N} C S\left(z_{N-1}\right), \text { for } N \geq 2 . \\
& \sigma_{a}=\sigma_{1}(1-C S(\infty))=\sigma_{1}, \text { for a homogeneous half-space }(N=1),
\end{aligned}
$$

where $C S$ could be either $C S_{V}$ or $C S_{H}$ depending on the orientation of dipoles. The total number of the layers is $N$. The layer numbering is such that the one nearest to the surface is identified by $j=1$. The normalised depth $z_{j}$ is measured from the surface to the lower boundary of a layer $j$.

It is useful to know how much of secondary-field signals contributes from a body of soils from the surface down to a certain depth. It is a complementary concept to the CS function. The normalised depth of soils with $p(0 \leq p \leq 1)$ contribution is

$$
\begin{aligned}
& z=\frac{\sqrt{p(2-p)}}{2(1-p)} \text { for a vertical dipole mode, } \\
& z=\frac{p(2-p)}{4(1-p)} \text { for a horizontal dipole mode, }
\end{aligned}
$$

The effective depth of investigation is commonly determined by setting $p=0.7$ which amounts to about 1.59 and 0.76 times the inter-coil spacing for the vertical and horizontal dipole modes, respectively.

The cumulative sensitivity function (based on the low-induction number assumption) is still widely used but can be limited mainly in very conductive environment (Callegary et al., 2007, 2012;

Andrade et al., 2016). Indeed, the shape of the cumulative sensitivity function does not depend on the electrical conductivity of the layers. An alternative approach consists in using Maxwell's equation that Wait (1982) derived for a 1D layered earth. This strategy has been successfully used in a number of studies (e.g. Lavoué et al., 2010; von Hebel et al., 2014; von Hebel et al., 2019; Hanssens et al., 2019).

As discussed above, EMI instruments usually output apparent electrical conductivity values for each unique combinations of coil orientations and separations. Given multiple apparent values for one position, it is possible, using the shape of the CS function for instance, to rebuild the profile of depthspecific electrical conductivity. This process is called inversion and is widely employed in other geophysical methods such as electrical resistivity method discussed in section 4. Inversion of EMI data can be challenging given the smaller number of measurements at each location, but when 
successful provides a vertical profile of electrical conductivity. While a full description of EMI inversion is out of the scope of this chapter, useful information is provided by von Hebel et al. (2019) and Monteiro Santos (2004). An example of the inversion is shown in Figure 3.3(A). Commercial software such as EM4Soil (Monteiro Santos, 2004) or Aarhus workbench (Auken et al., 2015) or open-source ones such as EMagPy (McLachlan et al., 2021), SimPEG (Heagy et al., 2017) and pyGIMLi (Rücker et al., 2017) are examples of software able to perform EMI inversion.

\subsection{Applications of EMI}

The measurement of electrical conductivity from EMI instruments have been extensively used for mapping different properties and states such as soil salinity (Corwin, 2008), water content (Corwin and Rhoades, 1984), soil texture (Triantafilis and Lesch, 2005) or soil organic matter (Huang et al., 2017). EMI mapping of agricultural fields can serve to delineate management zones (King et al., 2005; Rossi et al., 2018, Moral and Serano, 2019). Hence enabling spatially tailored crop management for precision agriculture.

Often, a key issue remains to understand how the electrical conductivity is related to a soil property of interest. For instance, Korsaeth et al. (2008) showed that maps of electrical conductivity obtained from EMI measurements could be used to map soil organic matter. This was because soil organic matter was proportional to the soil water content by virtue of the relationship between soil organic matter and porosity. Identically linking apparent electrical conductivity to soil moisture content is challenging and often results in site-specific relationships. Calamita et al. (2015) presents a review of the different soil moisture content - electrical conductivity relationships from multiple studies. In field studies where small variations between treatments are measured, accounting for the spatial heterogeneity of soil moisture - electrical conductivity relationships is useful to improve the discriminatory power of geophysical data (Blanchy et al., 2020c).

A way forward is the use of time-lapse surveys that enables the isolation of the dynamic component of the electrical conductivity which can be related, under some circumstances, to the change in soil moisture (Blanchy et al., 2020a; Robinson et al., 2012; Martini et al., 2017). The time-lapse approach consists in subtracting a reference survey from other surveys, hence allowing the removal of the static contribution of electrical conductivity from soil texture, for example.

To allow quantitative application, EMI measurements often needs to be calibrated against other soil conductivity data, for example from electrical resistivity surveys (Lavoué et al., 2010; Shanahan et al., 2015; von Hebel et al., 2019). Figure 3.3 shows the progressive patterns of soil drying over time by wheat estimated with EMI, ERT, neutron probe and penetrometer measurements. The penetrometer could not be manually operated later than 30th April because the soil became too strong as it dried, while the other three modalities were successfully applied afterwards. However, the penetrometer data clearly demonstrated soil drying with depth and over time earlier in the season. The other three methods returned considerable change of metrics to reflect soil drying from April to June, but registered insignificant variations during June suggesting that the soils were already relatively dry by then. The temporal patterns of soil drying recorded by EMI compare well with those obtained with a neutron probe. 

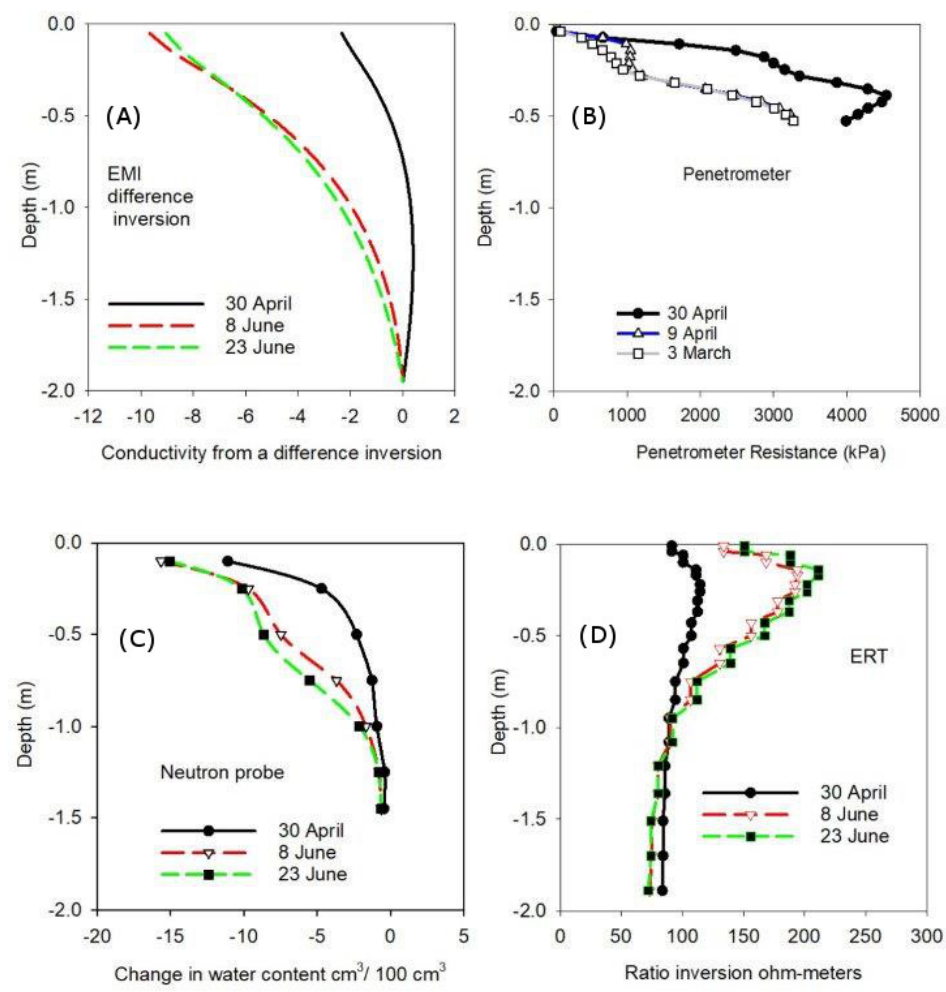

Figure 3.3 Comparison of EMI and other data from a 2015 survey of a wheat field: These data were collected on Warren field, Woburn, UK. The effect of temporal patterns in soil drying with depth on data determined from the inversion of ERT (D) and EMI (A) data, penetrometer measurements (B) and neutron probe $(\mathrm{C})$ measurements is shown. EMI and ERT data are obtained from the inversion routine that provides a continuous distribution over depth (From Whalley et al., 2017).

Figure 3.4 shows how changes in apparent electrical conductivity can be correlated with plant height and leaf area in wheat. This relationship is predicated on the assumption that a change in apparent conductivity is proportional to a change in water content (Whalley et al., 2017), or root water uptake, and hence crop growth. The electrical conductivity in Figure 3.4 was measured by an operator, guided by the tramlines spaced $36 \mathrm{~m}$, carrying an EMI instrument and a GPS receiver unit; for the field shown in Figure 3.4, the EMI survey can be done in a half day. The sampling locations of crop data were designed to have statistical significance.
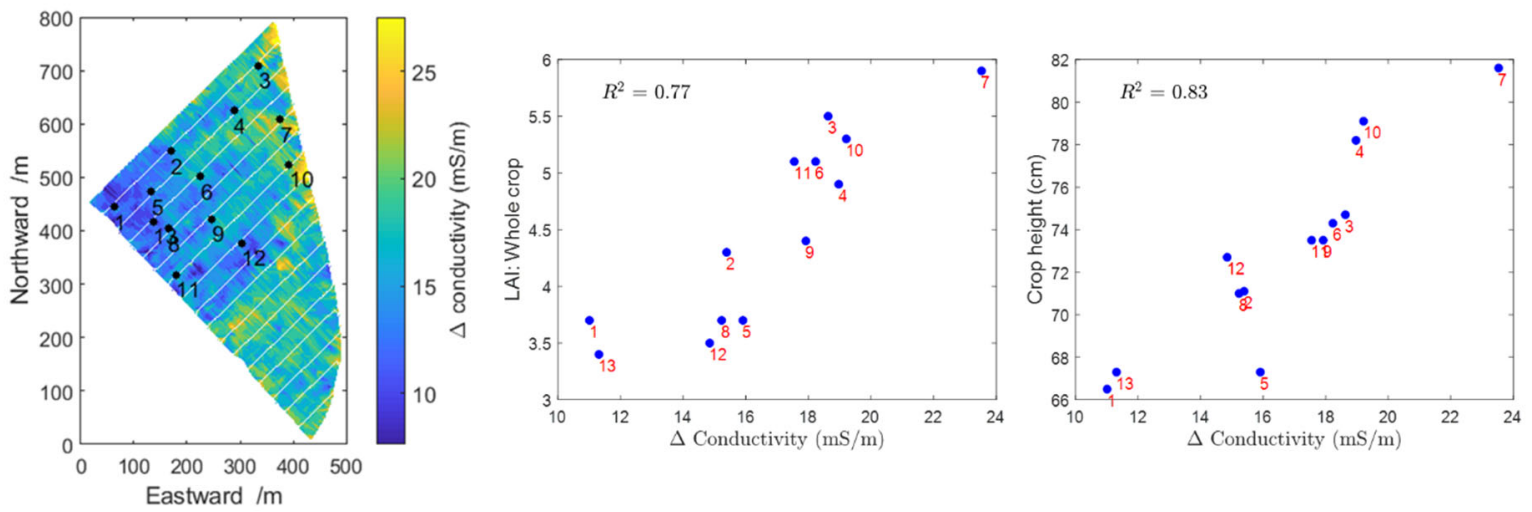

Figure 3.4 A map of the change in apparent conductivity between February and July 2019 obtained with a GF Instruments Mini-Explorer EMI instrument in vertical dipole mode $(0.32 \mathrm{~m}$ coil spacing) on a field near Cheddington, UK. At various locations in the field the height and leaf area index of wheat were measured and these are plotted against the change in apparent 
conductivity. The numbers from 1 to 13 identify the locations of crop data sampling. The white curves in the image show the survey path of EMI acquisition.

Information collected from EMI surveys can also be used to improve simulation of the crop productivity (Brogi et al., 2019; Brogi et al., 2020). Zhu et al. (2013) used EMI maps to help explain variation in crop yield in terms of soil moisture and clay content. They developed an approach for using EMI data to help develop a functional map of soil variation in time and space to explain crop yield.

\section{Electrical resistivity}

The resistivity method requires galvanic contact with the soil (Binley and Kemna, 2005) and hence is more invasive than EMI. The method is based on injecting current between a pair of electrodes (A and $B$ ) and measuring the voltage difference between another electrode pair ( $\mathrm{M}$ and $\mathrm{N}$ ). Figure 4.1 illustrates three quadrupole $(A, B, M, N)$ configurations. The measurement provides an apparent resistivity (the equivalent electrical resistivity of the ground if it were homogenous). Increasing the electrode spacing results in a deeper depth of investigation. Measurements are typically made with an array of several tens of electrodes installed along a transect, providing a 2D vertical section of resistivity ( $3 \mathrm{D}$ images can be derived from data using multiple transects). For such applications the term electrical resistivity tomography (ERT) is commonly used. It requires the application of inverse methods (as discussed below) to determine the spatial distribution of resistivity. Mobile methods have also been developed in which the ground contact is achieved using heavy electrodes (e.g. Sørensen, 1996) or coulter-based electrodes (Corwin and Lesch, 2005; Panissod et al., 1998; Reyes et al., 2018). Such approaches typically involve making measurements on a few voltage electrode pairs and thus can be used, like EMI, to provide estimate of resistivity at different depths. Mobile systems are limited to relatively flat sites with limited vegetation (due to the disturbance inevitable from the towing vehicle).

The spatial distribution of resistivity $\rho(x)$ is defined in Poisson's equation (Binley, 2015; Binley and Slater, 2020):

$$
\nabla \cdot\left(\frac{1}{\rho(x)} \nabla V(x)\right)=-I \delta\left(x_{0}\right)
$$

in which $V(x)$ represents the spatial distribution of the electric voltage or potential subject to a point current source with strength $I$ located at $x_{0}$. The Dirac delta is denoted by $\delta$ and $\nabla$ is the gradient operator. For an idealised subsurface of uniform resistivity $\rho$ with current electrodes on the flat surface of the soil, the half-space fundamental solution of Eq. (4.1) is

$$
V(r)=\frac{I \rho}{2 \pi r},
$$

where $r$ is the distance from the current source when the current sink is located at infinity. The voltage difference can be calculated by

$$
\Delta V=\frac{I \rho}{2 \pi}\left(\frac{1}{A M}-\frac{1}{B M}-\frac{1}{A N}+\frac{1}{B N}\right),
$$

where $\mathrm{AM}$ is the distance between electrodes $\mathrm{A}$ and $\mathrm{M}$, etc.

The most commonly used quadrupole configurations are the dipole-dipole, Schlumberger and Wenner configurations (Figure 4.1). The receiver (voltage) electrodes of the Schlumberger and Wenner arrays are placed within their transmitter (current) pair; this arrangement can provide relatively strong voltage signals at the receiver pair. By contrast the dipole-dipole array has its voltage pair outside and away from the current electrodes; this can cause weak voltage signal at the receiver pair especially for large distance between the two pairs. 

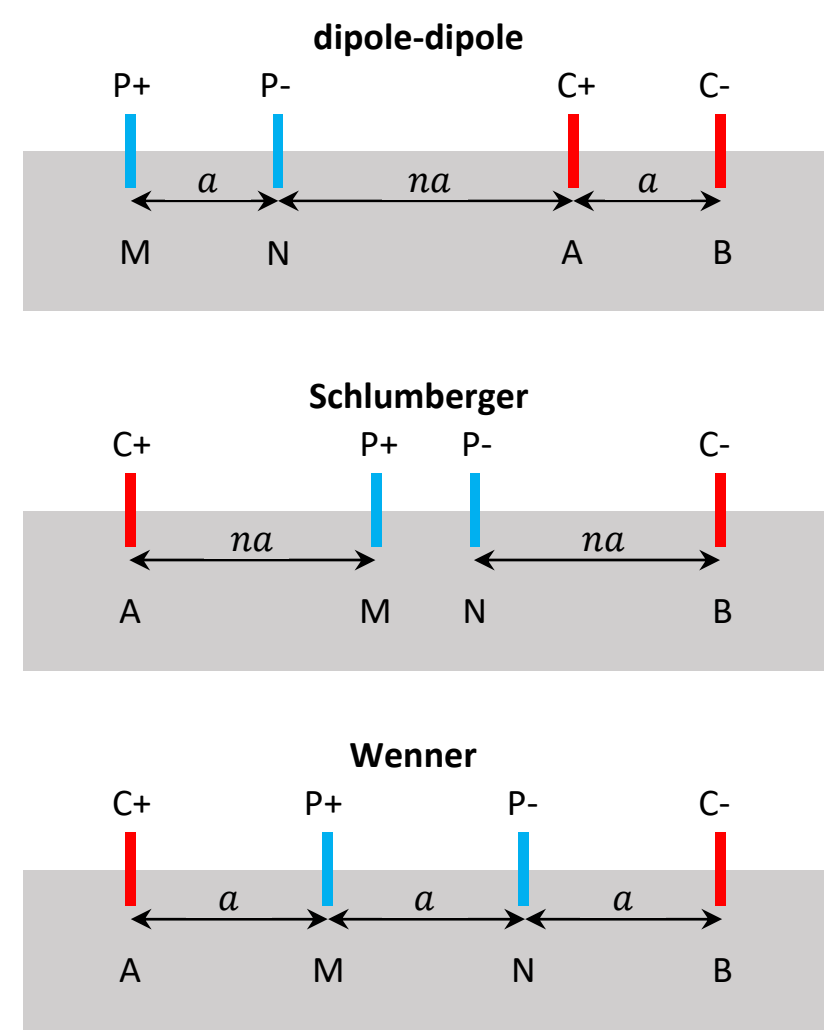

Figure 4.1. Schematic diagrams of dipole-dipole, Schumberger and Wenner arrays. The current pair is denoted by $\mathrm{C}+$ and $\mathrm{C}-(\mathrm{A}$ and $\mathrm{B})$, while the voltage pair is by $\mathrm{P}+$ and $\mathrm{P}-(\mathrm{M}$ and $\mathrm{N})$. The design separation is indicated by $a$ with an integer $n$.

Among these arrays, the dipole-dipole configuration is realised by setting the same spacing for current and voltage dipoles $(\mathrm{AB}=\mathrm{MN}=a)$ on the surface and the separation na between the nearest electrodes of these two dipole sets (with an integer $n$ ). Then, the apparent resistivity $\rho_{\mathrm{a}}$ of the dipole-dipole array may be calculated by (Binley, 2015)

$$
\rho_{\mathrm{a}}=\operatorname{\pi an}(n+1)(n+2) \Delta V / I,
$$

where $I$ is the injected current and $\Delta V$ is the measured voltage difference.

The resistivity in Eq. (4.2) is an apparent resistivity from the measurement and can be a true resistivity of the subsurface only if the subsurface is homogeneous and its surface is flat, which is an unlikely scenario in real applications. Therefore, inverse methods have to be applied to determine the resistivity structure of the subsurface (Binley, 2015; Binley and Slater, 2020). The depth of investigation, defined as a layer contributing the maximum amount to the total measured signal, of a dipole-dipole array is $0.18 \mathrm{~L}$ for homogeneous subsurface (Roy and Apparao, 1971) which is deeper than the Schlumberger $(0.125 L)$ and Wenner $(0.11 L)$ arrays; here, $L$ being the distance between the two extreme active electrodes. For example, ERT measurements shown in Figure 3.3(D) (and later in Figures 4.3 and 4.4) were carried out by arrays of the dipole-dipole configuration having 96 electrodes with $32 \mathrm{~cm}$ spacing between adjacent electrodes. The vertical resolution of a dipoledipole array can be poorer than the other two array configurations, but its lateral resolution is better. The Schlumberger array has a weak sensitivity to the lateral variability which is however advantageous when it comes to vertical exploration; hence, it is commonly used for vertical electrical sounding (Binley, 2015; Binley and Slater, 2020).

Due to advances in multi-channel switching systems in data acquisition, modern-day ERT measurement systems can measure on a number and configuration of electrodes. A resulting 2D image was traditionally presented in a pseudosection in which the apparent resistivities from individual four-electrode units are discretely marked in vertical and lateral positions according to the 
geometric configuration of the four electrodes. However, the pseudosection is merely a way of graphically presenting the apparent resistivity; hence, the subsurface structure of resistivity is not easily gleaned from the pseudosection. Nowadays, inverse methods are routinely used to determine an image of the subsurface resistivity that is consistent with the suite of apparent resistivity measurements.

Forward models are essentially to return a synthetic (or simulated) apparent resistivity (or equivalent parameters) for a given set of underground structure and distribution of true resistivity by solving Eq. (4.1). The problem is usually handled numerically for more general geometries of $2 \mathrm{D}$ and 3D by implementing the finite difference method or the finite element method (Binley, 2015). The spatial region of interest is first discretised to approximate the area by either structured or unstructured meshes; then, local resistivities are assigned to (or solved at) in cells (or elements) of the mesh which represent the degree of freedom for the problem.

The goal of inverse methods is to find a set of model parameters which reduces the difference between the measured data and the simulated data from forward models by means of numerical optimisation. Least-squares fitting is commonly used for this purpose by minimising the sum of the squares of the difference between the observed data and the forward model outputs. The goodness of fit for this purpose may be expressed by (Binley and Kemna, 2005)

$$
\Phi_{d}=\left\|W_{d}(d-F(m))\right\|^{2}=(d-F(m))^{T} W_{d}^{T} W_{d}(d-F(m)),
$$

where $d$ is the column vector composed of the observed data, $F(m)$ is the output of the forward model with model-parameter vector $m$. A matrix of data weighting is $W_{d}$; for the case of uncorrelated errors, it is a diagonal matrix with the inverse of data errors. The superscript $T$ represents the transpose of a vector or matrix.

There are many numerical optimisation algorithms to minimise Eq. (4.3). In geophysical inversions, minimisation of Eq. (4.3) may lead to non-unique or unstable inversions. Therefore, some level of constraint is needed to guide the solution. One of the most successful and widely-adopted approaches in this regard is to introduce the smoothness constraint by spatial regularisation. Regularisation in this context can be implemented by considering a model penalty term:

$$
\Phi_{m}=\left\|W_{m} m\right\|^{2}=m^{T} W_{m}{ }^{T} W_{m} m=m^{T} R m
$$

Here, the spatial smoothness of the model parameters is constrained by a roughness matrix $R$ which is usually a tridiagonal matrix and composed of a model-weighting matrix $W_{m}$.

The data and model misfit terms, $\Phi_{d}$ and $\Phi_{m}$, respectively, can be combined by adding the two with an extra proportionality coefficient:

$$
\Phi=\Phi_{d}+\alpha \Phi_{m}
$$

which is minimised instead of $\Phi_{d}$ alone. The scalar regularisation parameter $\alpha$ can be fixed throughout the optimisation or adjusted by iterative reduction starting from a large value. Minimisation of Eq. (4.4) can be carried out by using the Gauss-Newton approach (Binley and Kemna, 2005; Binley and Slater, 2020):

$$
\begin{aligned}
& \left(J^{T} W_{d}^{T} W_{d} J+\alpha R\right) \Delta m=J^{T} W_{d}^{T} W_{d}\left(d-F\left(m_{i}\right)\right)-\alpha R m_{i} ; \\
& m_{i+1}=m_{i}+\Delta m,
\end{aligned}
$$

where $J$ is the Jacobian matrix; $m_{i}$ is a set of model parameters at the $i$ th iteration. $\Delta m$ represents the amount of updates in model parameters.

The approach used above is commonly adopted for analysis of ERT data. For example, they are implemented in an ERT freeware R2 (http://www.es.lancs.ac.uk/people/amb/Freeware/R2/R2.htm); its GUI environment is also available in a Python-based open source software ResIPy (Blanchy et al., 2020d). Binley (2015) describe a range of modifications to the approach (including the analysis of time-lapse data) and more information on the inversion process. 


\subsection{Applications of electrical resistivity}

ERT is commonly used to image variations in resistivity associated with soil texture. In a few cases it has been used, in time-lapse mode, to assess variations of spatial changes of resistivity due to soil water, e.g. the uptake by roots (Whalley et al., 2017). The photograph (Figure 4.2) below shows an ERT array connected to an instrument capable of making the measurements shown schematically in Figure 4.1.

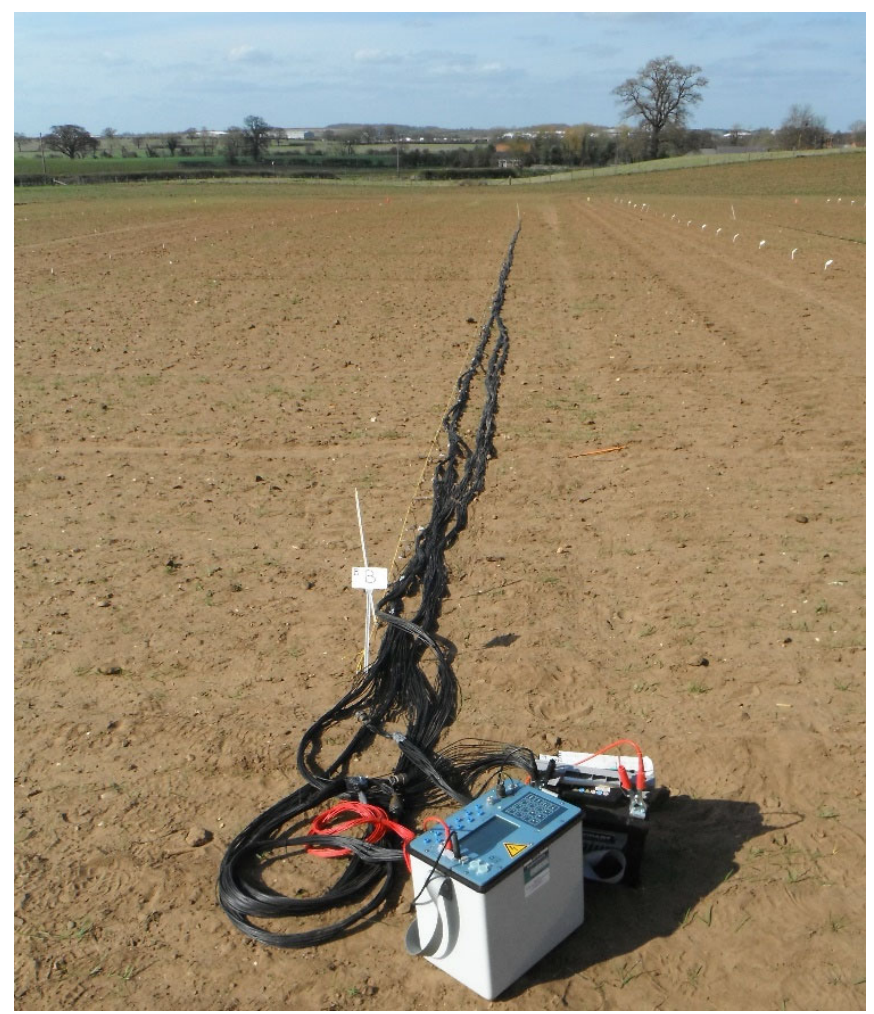

Figure 4.2 An ERT instrument connected to an ERT array set in Rothamsted's Experimental Farm at Woburn, Bedfordshire, UK.

In this application the ERT arrays were installed after experimental plots were sown, with the purpose of monitoring soil drying. The plots were approximately $2 \mathrm{~m}$ wide and $10 \mathrm{~m}$ long and the arrays were laid out to give a $2 \mathrm{~m}$ ERT image of consecutive plots. Figure 4.3 shows resistivity changes with time. It indicates that by July resistivity increases can be observed at depth of nearly $1 \mathrm{~m}$ and by inference soil dry to that depth. The names of the different wheat lines are indicated on Figure 4.3 along with a fallow plot with no wheat, and hence no drying, was used for the purpose of reference. 


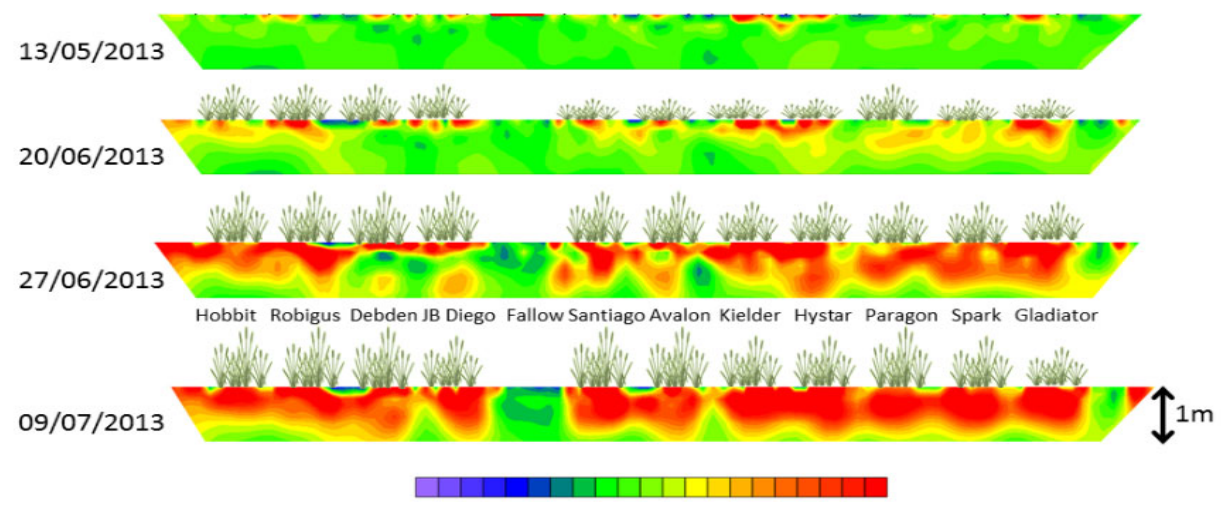

More conductive No change in resistivity More resistive

Figure 4.3 This shows a time-lapse ERT image showing changes in resistivity (from 23rd April 2013) because of soil drying by different winter wheat varieties (indicated). A fallow plot is also shown. The drier the soil the more resistive it becomes. The plots are approximately $2 \mathrm{~m}$ in width.

At the study site of Whalley et al. (2017) there are two types of soil: one sandy with a cemented hard layer at a depth of approximately $30 \mathrm{~cm}$ and one with a deep clay rich profile. Figure 4.4 compares spatial resistivity maps on these different soils in July following soil drying. It can be seen clearly that on the sandy soil (Butt Close) that only the very surface layers are dried by roots. In contrast, on the clay rich profile with no cemented layer (Warren Field) there is soil drying to depth.

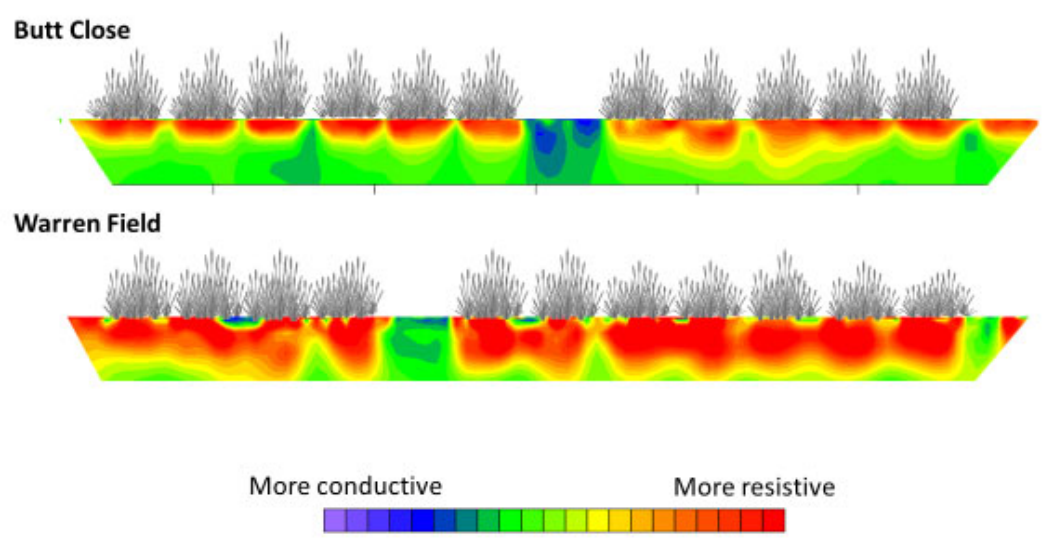

Figure 4.4 A comparison of ERT difference images (change from April to July 2013) following soil drying by wheat. The top image is from Butt Close near Woburn, UK which is a sandy site with a cemented layer at a depth of approximately $30 \mathrm{~cm}$. At this site soil drying is limited to the shallow layers (less than $30 \mathrm{~cm}$ depth). The bottom image is from a neighbouring field with a deep clay rich profile. This site shows soil drying to depth. Each plot is approximately $2 \mathrm{~m}$ in width.

While ERT methods may not give accurate soil water content data compared with a specialised soil water content sensor, they do give a wealth of spatial information. The spatial resolution depends on the electrode spacing and resolution, but in a field application the greatest resolution is likely to be in the order of several centimetres. 
ERT was also employed to monitor the three-dimensional distribution of soil water content in a maize field (Beff et al., 2013), in which the effect of plants and rainfall event was investigated during the growing season. They deduced the water contents from the inversion of ERT data which were validated by TDR measurements. The high resolution of the ERT-based water content distribution allowed the identification of the drying pattern around maize root profiles.

A system of permanently installed ERT arrays was used to measure the temporal and spatial variation of the resistivities in an irrigation experiment over a three-year duration (Dahlin et al., 2014). They also inverted the ERT data to construct the 2D and 3D images of resistivity patterns and observed the resistivity changes linked to the irrigation quantities and the growth of willow. Their result also confirmed the effectiveness of their groundwater sampling protocol carried out in pipes installed in depth. Other examples of the use of ERT in crop studies include Michot et al. (2003) and Garré et al. (2011). Macleod et al. (2013) used ERT to help identify grass varieties that enhance soil structure and potentially minimise the risk of flooding. Blanchy et al. (2020b) uses hourly ERT measurements to couple below-ground processes with the evolution of above-ground traits under a high-throughput automated phenotyping platform.

ERT arrays have also been used in laboratory conditions. Rings of electrodes can be installed around the circumference of soil cores. Such configuration can be used to determine the 3D distribution of resistivity. Using this setup, Binley et al. (1996) demonstrated the effectiveness of ERT in solute tracing experiment in soils, using the ERT images to identify preferential flow pathways in the core. In a subsequent study, Koestel et al. (2008) used a combination of ERT and TDR measurements to develop solute transport properties of a soil core. 


\section{Acoustic-to-seismic coupling}

When the soil is assumed as homogeneous and isotropic elastic solid without voids, then there are two waves which propagates separately: P-wave and S-wave. The phase velocity of P-wave is well established as

For S-wave, we have

$$
V_{p}=\sqrt{\frac{K+4 \mu / 3}{\rho}}
$$

$$
V_{s}=\sqrt{\mu / \rho}
$$

where the mass density of the solid is $\rho$; two elastic moduli are $K$ for bulk modulus and $\mu$ for shear modulus (also known as Lamé's second parameter).

For poroelastic media, models for two-phase poroelastic materials comprised of solid and a single fluid (either gas or liquid) have been widely studied since the seminal works by Biot (1956a, 1956b) and have been expanded by many researchers since then. To some extent, the theory behind twophase modelling can be judged almost matured while interesting applications are still being reported. By contrast, three-phase modelling is still being actively studied despite the first of the kind was reported some 55 years ago by Brutsaert (1964).

Just as simple as their phase velocities (Equations 5.1 and 5.2), the wave numbers of isotropic elastic solids are also succinctly expressed: $\omega \sqrt{\rho /(K+4 \mu / 3)}$ for a compressional wave and $\omega \sqrt{\rho / \mu}$ for a shear wave. However, for fluid-saturated two-phase porous materials, the wavenumbers $\left(l_{1}\right.$ and $\left.l_{2}\right)$ of two compressional waves and the wavenumber $\left(l_{3}\right)$ for a shear wave can be obtained by solving the following equations (Shin et al., 2013, 2017; Stoll, 1974)

$$
\begin{gathered}
\left(\rho_{f} \omega^{2}-C l_{1,2}^{2}\right)^{2}=\left(\rho \omega^{2}-H l_{1,2}^{2}\right)\left(\rho_{f} q^{2} \omega^{2} / \Omega-M l_{1,2}^{2}+\mathrm{i} \omega F \eta / k\right) \\
\left(\rho_{f} \omega^{2}\right)^{2}=\left(\rho \omega^{2}-\mu l_{3}^{2}\right)\left(\rho_{f} q^{2} \omega^{2} / \Omega+\mathrm{i} \omega F \eta / k\right)
\end{gathered}
$$

with fluid density $\left(\rho_{f}\right)$, bulk density of soil $(\rho)$, tortuosity $\left(q^{2}\right)$, fluid permeability $(k)$, porosity $(\Omega)$, fluid viscosity $(\eta)$, imaginary unit (i): the time-harmonic convention of $\exp (-\mathrm{i} \omega t)$ is used with time $t$. The elastic constants $H, C, M$ and $D$ are further defined as (Stoll, 1974)

$$
\begin{gathered}
H=\frac{\left(K_{r}-K_{b}\right)^{2}}{D-K_{b}}+K_{b}+\frac{4}{3} \mu \\
C=\frac{K_{r}\left(K_{r}-K_{b}\right)}{D-K_{b}} \\
M=\frac{K_{r}^{2}}{D-K_{b}} \\
D=K_{r}\left\{1+\Omega\left(K_{r} / K_{f}-1\right)\right\}
\end{gathered}
$$

with bulk modulus of the solid particle $\left(K_{r}\right)$, bulk modulus of the porous medium $\left(K_{b}\right)$, bulk modulus of fluid $\left(K_{f}\right)$, and shear modulus of the porous medium $(\mu)$. In reality, the soil matrix is unlikely to be perfectly elastic. To this effect, the imaginary part accounting for damping can be introduced to the bulk moduli $\left(K_{b}\right.$ and $\mu$ ) to incorporate the damping effect for elastic waves (Stoll, 1974). The details of the viscosity correction factor $(F)$ depends on a model of a pore structure idealised for given soils (Biot, 1956b).

\subsection{Model for acoustic-to-seismic coupling}


When waves propagating in poroelastic materials encounter layer boundaries, the amplitudes of the reflected and transmitted waves can be determined by solving a boundary value problem, as long as the wave numbers of the three component waves have been calculated for each poroelastic layer.

To solve the boundary value problem, equations of motions for each layer must be established. With a point source having axial symmetry, the wave fields can be represented by only two components of wave motions in the radial $(r)$ and vertical $(z)$ coordinates. When the height of an airborne acoustic source is $z_{s}$, the Green's function $\left(\psi_{0}\right)$ for an airborne layer and those $\left(\psi_{1, n}, \psi_{2, n}\right.$, $\left.\psi_{3, n}\right)$ for poroelastic waves in soils are (Shin et al., 2013; Tooms et al., 1993)

$$
\begin{gathered}
\psi_{0}(\xi, z)=\frac{1}{\beta_{0}} \mathrm{e}^{\mathrm{i}\left|z-z_{s}\right| \beta_{0}}+A_{0}^{\uparrow} \mathrm{e}^{-\mathrm{i} z \beta_{0}} \\
\psi_{1, n}(\xi, z)=A_{1, n}^{\downarrow} \mathrm{e}^{\mathrm{i}\left(z-d_{n}^{+}\right) \beta_{1, n}}+A_{1, n}^{\uparrow} \mathrm{e}^{\mathrm{i}\left(z-d_{n}^{-}\right) \beta_{1, n}}+A_{2, n}^{\downarrow} \mathrm{e}^{\mathrm{i}\left(z-d_{n}^{+}\right) \beta_{2, n}}+A_{2, n}^{\uparrow} \mathrm{e}^{\mathrm{i}\left(z-d_{n}^{-}\right) \beta_{2, n}} \\
\psi_{2, n}(\xi, z)=M_{1, n}\left[A_{1, n}^{\downarrow} \mathrm{e}^{\mathrm{i}\left(z-d_{n}^{+}\right) \beta_{1, n}}+A_{1, n}^{\uparrow} \mathrm{e}^{\mathrm{i}\left(z-d_{n}^{-}\right) \beta_{1, n}}\right]+M_{2, n}\left[A_{2, n}^{\downarrow} \mathrm{e}^{\mathrm{i}\left(z-d_{n}^{+}\right) \beta_{2, n}}+A_{2, n}^{\uparrow} \mathrm{e}^{\mathrm{i}\left(z-d_{n}^{-}\right) \beta_{2, n}}\right] \\
\psi_{3, n}(\xi, z)=A_{3, n}^{\downarrow} \mathrm{e}^{\mathrm{i}\left(z-d_{n}^{+}\right) \beta_{3, n}}+A_{3, n}^{\uparrow} \mathrm{e}^{\mathrm{i}\left(z-d_{n}^{-}\right) \beta_{3, n}}
\end{gathered}
$$

where $M_{1, n}$ and $M_{2, n}$ indicate the ratio of the fluid-borne wave to the soil frame-borne wave; $\beta$ with subscripts are the vertical wave numbers; $\xi$ is the horizontal wave number. The vertical coordinates of upper and lower soil boundary of a layer $n$ are denoted by $d_{n}^{+}$and $d_{n}^{-}$. The upward $\left(A_{m, n}^{\uparrow}\right)$ and downward $\left(A_{m, n}^{\downarrow}\right)$ amplitudes of Green's functions can be calculated by applying appropriate boundary conditions at layer interfaces. The systems of equations for the boundary conditions of each layer interface are then mapped together with those from others to form a linear system of a global matrix (Tooms et al., 1993). Then, the amplitudes of propagating wave components in layers are calculated all together through standard methods for solving a system of linear equations. Once these amplitudes $\left(A_{m, n}^{\uparrow}\right.$ and $\left.A_{m, n}^{\downarrow}\right)$ are determined for each layer and wave types, the acoustic pressure in the fluid (air) layer and particle velocities on the ground can be calculated; for detailed procedure, see Shin et al. (2013) and Tooms et al. (1993).
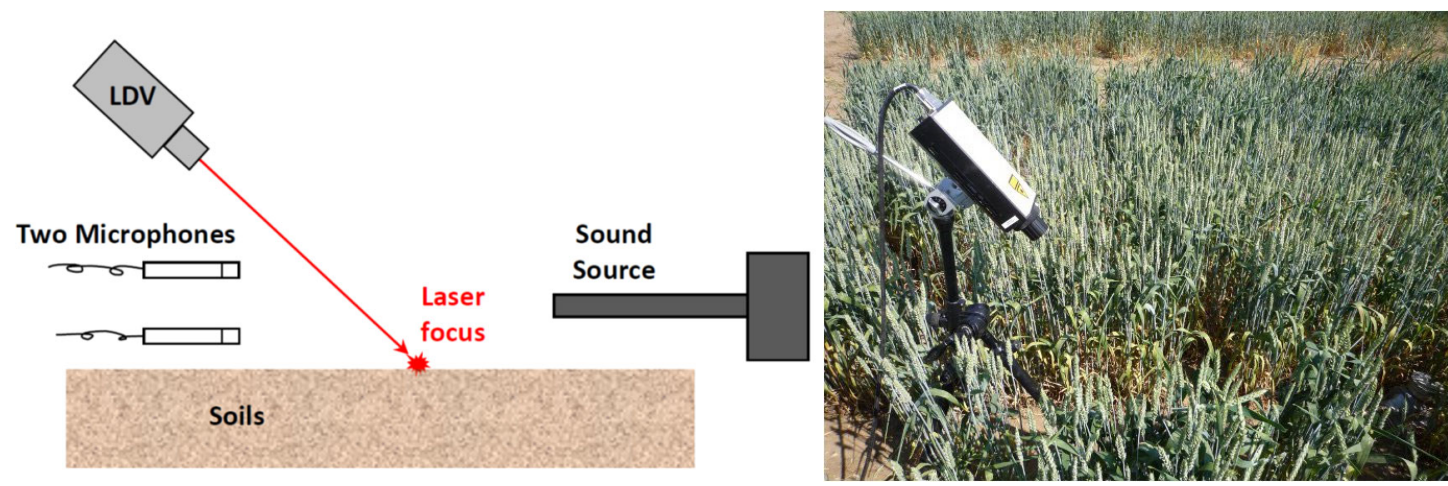

Figure 5.1. Schematic diagram and photograph of measurement configuration showing acoustic source, two microphones and an LDV (laser Doppler vibrometer). The left-hand side is adapted from Shin et al. (2013).

These simulated acoustic pressure and particle velocities on soil surface were compared to the measured counterparts. The acoustic pressure was measured by a pair of microphones; the soil particle velocity was recorded by a laser Doppler vibrometer (LDV). An acoustic-source system was composed of a compression driver extended by a metal pipe (Figure 5.1). Instead of one-to-one comparisons, the measured and modelled signals were compared in terms of ratios: that is, transfer functions. Then, the numerical optimisation is carried out to minimise the differences between the 
transfer functions from the measurement and the simulation. For details about the optimisation procedure, see Shin et al. (2013).

The minimum set of properties required by a numerical optimization is composed of air permeability, porosity, complex shear modulus, Poisson's ratio and the layer thickness for each layer: these are updated during the optimization. The other properties in the poroelasticity model are well documented. In place of complex shear modulus, we adopted the loss factor and Swave speed which were first converted to the shear modulus, then to the penetration resistance.

\subsection{Applications of acoustic-to-seismic coupling model}

Field measurements were carried out on the Woburn Experimental Farm operated by Rothamsted Research, UK. The acoustic-to-seismic coupling measurements were made in plots of loamy sand with different winter wheat varieties of Paragon and Hystar hybrid. A fallow plot was also included for comparison.

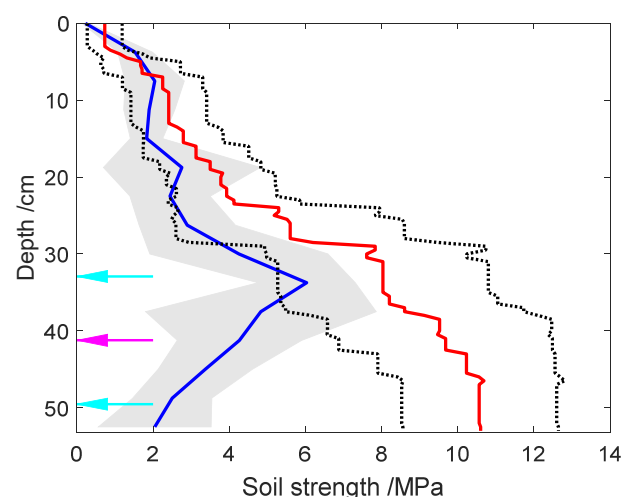

(a)

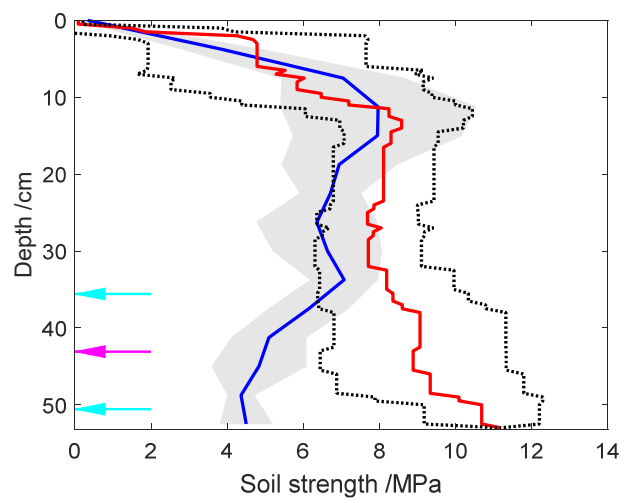

(c) (b)

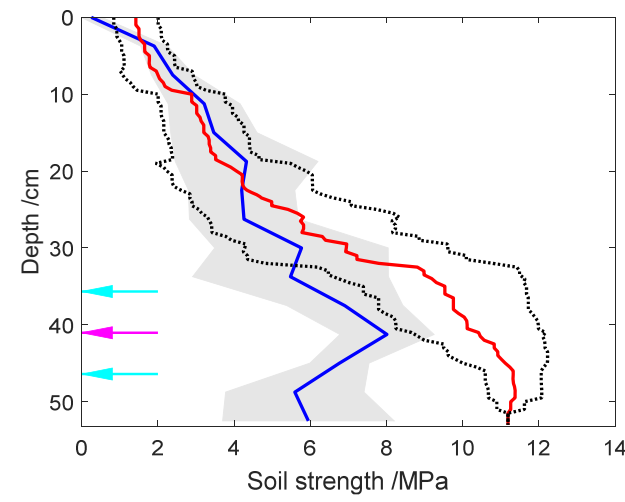

Figure 5.2. Plots of soil strength measured by a penetrometer (28 June) and deduced from measurements of the acoustic-to-seismic coupling ( $a$ and $b$ on 26 June; $c$ on 27 June) for the experimental plots: (a) fallow (b) Paragon variety and (c) Hystar hybrid variety. The mean and standard deviation of (i) penetrometer readings, (ii) the acoustic-to-seismic soil strength and (iii) estimated hardpan depth are illustrated by (i) blue lines and grey boundaries, (ii) red lines and black dotted lines, and (iii) magenta arrows and cyan arrows, respectively. Adapted from Shin et al. (2017).

Figure 5.2 compares the soil strength profile deduced from the acoustic-to-seismic coupling (on 26 and 27 June) with that measured by a penetrometer (on 28 June). These are the extracts from Shin et al. (2017); full results can be found therein. The blue line inside the grey strip shows the arithmetic mean of five penetrometer readings at a given depth and the boundaries of the grey region indicate one standard deviation. In some cases, the soil was too strong for penetrometer 
operation in depth; this may have resulted in an underestimated penetration resistance and a smaller variance.

The red line in Figure 5.2 indicates the average soil strength deduced from the acoustic-to-seismic coupling. The number of optimised results taken for the average is 12,28 and 9 , respectively for (a), (b) and (c) of Figure 5.2. The two dotted black lines on either side of the red lines are the estimates of a standard deviation at a given depth. There are three arrows: the magenta one represents the average of the estimated depths of a hardpan and the two cyan arrows indicate a standard deviation. The deduced depths of hardpans are similar among three plots.

The comparison in Figure 5.2 of soil penetration strength between the fallow plot and the other wheat plots suggests that as the crop grows it tends to extract more water from the soil than supplied by rain, leading to increased soil strength. The similarity between the penetrometer readings and deduced soil strength is also good, especially for the upper layers. The agreement is less encouraging in the lower layers, partly because some of the penetrometer operations were not successful at those depths and partly because of lack of high-fidelity low-frequency signals for the acoustic-seismic measurements.

It is emphasised that Figure 5.2 is the outcome of three independent efforts. Firstly, acoustic-toseismic coupling (measurements and numerical optimization) was carried out to estimate the shear modulus $(\mu)$. Secondly, a penetrometer was operated to measure the penetration resistance $(Q)$. Thirdly, there was an independently obtained relation between $Q$ and $\mu$. For Figure 5.2, we have adopted an empirical relation proposed by Gao et al. (2013):

$$
Q \approx(0.0286 \pm 0.0013) \mu+(-53.0 \pm 12.9 \mathrm{kPa}),
$$

for the arable loamy sand in the area for the acoustic-to-seismic measurements. The shear modulus from the optimization is about 35 times larger than the penetration resistance. Therefore, without help of Equation (5.3), it is not possible to observe good agreement of soil strengths from both acoustic-to-seismic coupling and penetrometer in the shallow layers in Figure 5.2.

\subsection{Deducing the soil water contents by wave-speed measurements}

Fluid-saturated two-phase models may describe the wave propagation in air-saturated sound absorbing materials or water-saturated sediments on sea floors. However, two-phase models can be too ideal to represent most of (arable) soils with partial water saturation, except low-level water contents as demonstrated in the previous section. In this regard, Brutsaert (1964) is widely credited to have initiated the theory of elastic wave propagation through unconsolidated unsaturated granular materials having three distinct phases of a solid and two immiscible fluids. Due to the introduction of the second fluid component, three compressional waves and one shear wave were predicted to propagate when the medium is unbounded. One noticeable shortcoming of his model was the lack of the inertial coupling between phase components as also pointed by others (Arora and Tomar, 2008; Lo and Sposito, 2013).

In his follow-up work (Brutsaert and Luthin, 1964), Brutsaert investigated the relationship between a wave speed and the soil moisture content. Among four waves, he focussed on the speed of the fastest wave which is the one closest to the P-wave in characteristics and hence often referred to as P1-wave (Lo and Sposito, 2013). Due perhaps to the lack of inertial coupling between different phases, Brutsaert contemplated the low frequency by proposing its velocity as:

$$
c=\sqrt{\frac{0.306 a p_{\mathrm{e}}^{1 / 3} Z}{\rho_{m} \Omega b^{2 / 3}}}
$$


with $p_{\mathrm{e}}=p_{\mathrm{t}}-p_{\mathrm{g}}-S p_{\mathrm{c}}$ where $p_{\mathrm{e}}, p_{\mathrm{t}}, p_{\mathrm{g}}$ and $p_{\mathrm{c}}$ are effective pressure, total pressure, equilibrium pressure in the gas, and capillary pressure in the liquid, respectively. The degree of saturation with liquid is $S$. The equation has the mass density $\rho_{\mathrm{m}}=\rho_{\mathrm{s}}+\rho_{\mathrm{g}}+\rho_{\mathrm{l}}$ with the masses of solid $\left(\rho_{\mathrm{s}}\right)$, gas $\left(\rho_{\mathrm{g}}\right)$ and liquid $\left(\rho_{\mathrm{l}}\right)$ per unit bulk volume. The porosity is denoted by $\Omega$. The factors $a$ and $b$ are empirical. The remaining term $Z$ is a nonlinear function of $b, p_{\mathrm{e}}$ and effective bulk modulus ( $\left.K_{\mathrm{eff}}\right)$. Brutsaert and Luthin (1964) adopted $K_{\text {eff }}=(1-S) K_{\mathrm{g}}+S K_{\mathrm{l}}$ with $K_{\mathrm{g}}$ and $K_{\mathrm{l}}$ for the bulk moduli of gas and liquid, respectively. Later, the choice of this specific formula of $K_{\text {eff }}$ was considered as a typing error by others (Flammer et al., 2001) who suggested a correct form might have been $K_{\text {eff }}^{-1}=$ $(1-S) K_{\mathrm{g}}^{-1}+S K_{\mathrm{l}}^{-1}$.

Despite the uncertainty on the use of $K_{\text {eff }}$, Brutsaert's model has been revisited with the aim of establishing the relationship between the wave speeds and the soil water contents (Adamo et al., 2009, 2010; Flammer et al.,2001; Sharma and Gupta, 2010). Their works were essentially conducted and reported as forward approaches (Shin et al., 2016); however, the rationales behind some of these efforts were investigating the feasibility of inverse tools. Here, by the forward method, it studies "the velocity of sound in soils ... by function of the moisture content" which is actually part of the article title of Brutsaert and Luthin (1964). By contrast, the inverse model aims to solve "the moisture content ... by function of the velocity of sound in soils". Logically, the success of the former proposition (i.e. forward model) does not necessarily guarantee the success of the latter (i.e. inverse approach). More in-depth discussion of Brutsaert's model and its applications by others (Adamo et al., 2009, 2010; Flammer et al.,2001; Sharma and Gupta, 2010) can be found in Shin et al. (2016).

There is also a question whether the water content is a right parameter to investigate from the measurement of the elastic wave speeds in unsaturated soils (Shin et al., 2016). In Brutsaert's model, it is related to the occurrence of the water content and effective pressure (or water potential) as a product of $S p_{\mathrm{c}}$ in which whether $S$ is an appropriate parameter is also an interesting topic (Bishop and Blight 1963; Gray and Schrefler, 2001; Jennings and Burland, 1962; Khalili and Khabbaz, 1998; Nuth and Laloui, 2008); more discussion can be found in Shin et al. (2016). Lu and Sabatier (2009) and Lu (2014) demonstrated that the sound speed in the unsaturated soils is closely related to the water potential rather than the moisture content and temperature. In the case of shear waves, Whalley et al. (2012) reported that, at matric potentials higher than the air entry potential, $V_{S}$ in sands increased even at constant water content while the matric potential decreased. Therefore, in the context of possible inverse problems, the water potential could be the one to pursue rather than the water content.

Whether it is the water content or the water potential, its estimation based on the measurement of a single parameter, the elastic wave speed in this case, can be challenging even in the laboratory setting (Adamo et al., 2009, 2010; Sharma and Gupta, 2010), let alone in the field of arable soils. Additional information is required. As shown briefly in a previous section, Shin et al. $(2013,2017)$ demonstrated the feasibility of using the acoustic-seismic coupling method to deduce various soil properties non-invasively. The acoustic-seismic coupling means that the method has the potential to investigate the pore-related and structure-related properties at the same time by a single set of related measurements. However, one of the theoretical bases behind the method is a fluidsaturated poroelastic model. Therefore, the method is currently limited to either dry or lowmoisture soils. There is certainly room for improving the method by incorporating the three-phase poroelastic models to account for more general status of unsaturated soils. In this implementation, the hysteretic nature (Gallipoli et al., 2003; Gregory et al., 2010; Lu and Sabatier, 2009) of soil moisture-suction relationships may need to be known.

\section{Summary}


There are several geophysical methods which can deduce the characteristics of agricultural soils by measuring physical properties such as electric resistivity (or conductivity), elasticity constants, etc. These are electrical resistivity method, electromagnetic induction method, induced polarisation, ground penetrating radar, nuclear magnetic resonance, and acoustic-seismic methods. Among these, we have focused on three: electromagnetic induction, electrical resistivity, and acoustic-to-seismic. For each method, a basic theoretical background has been briefly introduced, followed by agricultural applications: we have focused on the spatial and temporal mapping of soil water or drying by crops.

In the electromagnetic induction method, time-varying primary magnetic field induces very small eddy currents in the ground resulting in a secondary magnetic field. From the ratio of the primary to the secondary magnetic field, apparent electrical conductivity can be measured. Knowing the cumulative sensitivity pattern, inversion can be applied to deduce the depth-specific conductivity. The measurement itself can be done swiftly and non-invasively; hence it is widely used for surveying large areas, which can provide the basis for the precision agriculture applying spatially customised treatment within field (Corwin and Lesch, 2003; Lück, et al., 2009). For electromagnetic induction method, we presented the observation of the temporal pattern of soil drying by wheat, which was also accompanied by the measurement of electrical resistivity, penetration resistance and neutron probe. Another example was the correlation of apparent electrical conductivity with height and leaf area of wheat on the assumption that a change in soil conductivity is related to a change in soil water content associated with root water uptake.

The resistivity method requires galvanic contact with the soil. Basic sensors are often arranged in a quadrupole configuration of a pair of current-injecting electrodes and another pair of voltagemeasuring electrodes; nowadays, this configuration is extended in an array of numerous electrodes capable of 2D or 3D investigation due to advances in multi-channel switching systems. Measured apparent resistivity can be further processed with inverse methods to assess the spatial distribution of resistivity. This spatial information, likewise that of EMI, also helps estimate within-field variations required for successful application of precision farming. By using the electrical resistivity tomography, we presented a time-lapse image showing considerable changes in resistivity because of soil drying by different winter wheat varieties; by contrast, a fallow plot experienced least change. In another example, the presence of a cemented hard layer was identifiable by the analysis of tomography images: only the very surface layers are dried by roots in presence of a hard layer; otherwise, soil drying was observed to depth.

The acoustic-to-seismic method exploits the coupling mechanism between airborne acoustic source and underground seismic activity. The soil is treated as poroelastic (i.e., porous and elastic) material; hence, the model is sensitive to the soil elastic characteristics and porosity. The poroelasticity theory is incorporated with wave propagation model in layered media. Several soil physical properties can be estimated through numerical optimisation against measured acoustic-to-seismic transfer functions. As applications, the penetration resistance of wheat-growing soils is compared between the measurement by a penetrometer and the estimation made from shear modulus deduced from the acoustic-to-seismic method. It was shown that as the wheat grew, the soil strength increased due to extraction of water.

\section{Acknowledgments}

Rothamsted Research receives grant-aided support from the Biotechnology and Biological Sciences Research Council (BBSRC) through the Designing Future Wheat programme [BB/P016855/1] and the joint NERC/BBSRC ASSIST project (NE/N018117/1). We acknowledge support from BBSRC Crop 
Improvement Research Club (BB/J019461/1 and BB/J01950X/1). GB was supported by a Lancaster University - Rothamsted Research- CEH Graduate School for Environment PhD studentship.

\section{REFERENCES}

Adamo, F., Attivissimo, F., Fabbiano, L., and Giaquinto, N. (2009). "Velocity-moisture relationships for sandy soils: Experimental results and data analysis," IEEE. T. Instrum. Meas. 58, 311-317.

Adamo, F., Attivissimo, F., Fabbiano, L., Giaquinto, N., and Spadavecchia, M. (2010). "Soil moisture assessment by means of compressional and shear wave velocities: Theoretical analysis and experimental setup," Measurement 43, 344-352.

Algeo, J., Slater, L., Binley, A., Van Dam, R. L., and Watts, C. (2018). "A Comparison of GroundPenetrating Radar Early-Time Signal Approaches for Mapping Changes in Shallow Soil Water Content," Vadose Zone J. 17, 180001.

Allred, B. J., Daniels, J. J., and Ehsani, M. R. (Eds.), (2008). Handbook of agricultural geophysics, Boca Raton: CRC Press.

Andrade, F. C. M., Fischer, T., and Valenta, J. (2016). "Study of errors in conductivity meters using the low induction number approximation and how to overcome them." In Near Surface Geoscience 2016-22nd European Meeting of Environmental and Engineering Geophysics, Barcelona, Spain: EAGE.

Andrade, F. C. and Fischer, T. (2018). "Generalised relative and cumulative response functions for electromagnetic induction conductivity meters operating at low induction numbers: Relative and cumulative response functions," Geophys. Prospect. 66(3), 595-602.

Archie, G. E. (1942). "The electrical resistivity log as an aid in determining some reservoir characteristics," Trans. Am. Inst. Min. 146, 54-62.

Arora, A. and Tomar, S. K. (2008). "The effect of inertial coupling on seismic reflection amplitudes," Geophys. Prospect. 56, 643-654.

Auken, E., Christiansen, A. V., Kirkegaard, C., Fiandaca, G., Schamper, C., Behroozmand, A. A., Binley, A., Nielsen, E., Effers $\varnothing$, F., Christensen, N. B., Sørensen, K., Foged, N., and Vignoli, G. (2015). "An overview of a highly versatile forward and stable inverse algorithm for airborne, ground-based and borehole electromagnetic and electric data," Explor. Geophys. 46(3), 223-235.

Beff, L., Günther, T., Vandoorne, B., Couvreur, V., and Javaux, M. (2013). "Three-dimensional monitoring of soil water content in a maize field using electrical resistivity tomography," Hydrol. Earth Syst. Sci. 17, 595-609.

Binley, A. (2015). "Tools and techniques: Electrical methods," in Treatise on Geophysics, edited by G. Schubert (Elsevier, Oxford), Chap. 11.08, pp. 233-259.

Binley, A. and Kemna, A. (2005). "DC resistivity and induced polarization methods," in Hydrogeophysics, edited by Y. Rubin and S. S. Hubbard (Springer, Dordrecht, The Netherlands), Chap. 5, pp. 129-156. 
Binley, A., Henry-Poulter, S., and Shaw, B. (1996). "Examination of Solute Transport in an Undisturbed Soil Column using Electrical Resistance Tomography", Water Resour. Res. 32(4), 763-769.

Binley, A., Hubbard, S.S., Huisman, J. A., Revil, A., Robinson, D.A., Singha, K., and Slater, L. D. (2015). "The emergence of hydrogeophysics for improved understanding of subsurface processes over multiple scales", Water Resour. Res. 51(6), 3837-3866.

Binley, A. and Slater, L. (2020). Resistivity and Induced Polarization: Theory and Applications to the Near-Surface Earth, Cambridge, UK: Cambridge University Press.

Biot, M. A. (1956a). "Theory of propagation of elastic waves in a fluid-saturated porous solid. I. low-frequency range," J. Acoust. Soc. Am 28, 168-178.

Biot, M. A. (1956b). "Theory of propagation of elastic waves in a fluid-saturated porous solid. II. higher frequency range," J. Acoust. Soc. Am 28, 179-191.

Bishop, A. W. and Blight, G. E. (1963). "Some aspects of effective stress in saturated and partly saturated soils," Géotechnique 13, 177-197.

Blanchy, G., Watts, C.W., Richards, J., Bussell, J., Huntenburg, K., Sparkes, D.L, Stalham, M., Hawkesford, M.J., Whalley, W.R. and Binley, A. (2020a). "Time-lapse geophysical assessment of agricultural practices on soil moisture dynamics," Vadose Zone J., 19(1), e20080.

Blanchy, G., Virlet N., Sadeghi-Tehran P., Watts C.W., Hawkesford M.J. Whalley, W.R. and Binley A. (2020b). "Time-Intensive Geoelectrical Monitoring under Winter Wheat," Near Surf. Geophys., 18(4), 413-25.

Blanchy, G., Watts C.W., Ashton R.W., Webster C.P., Hawkesford M.J., Whalley W.R. and Binley A. (2020c). "Accounting for Heterogeneity in the $\theta-\sigma$ Relationship: Application to Wheat Phenotyping Using EMI," Vadose Zone J., 19(1).

Blanchy, G., Saneiyan, S., Boyd, J., McLachlan, P., and Binley, A. (2020d). "ResIPy, an intuitive open source software for complex geoelectrical inversion/modeling," Comput. Geosci. 137, 104423.

Brogi, C., Huisman, J. A., Herbst, M., Klosterhalfen, A., Weihermüller, L., Montzka, C., van der Kruk, J. and Vereecken, H. (2019). "Geophysics-based soil mapping improves the simulation of crop productivity at the field scale and beyond," Geophys. Res. Abs. 21, 7979.

Brogi, C., Huisman, J. A., Herbst, M., Weihermüller, L., Klosterhalfen, A., Montzka, C., Reichenau, T. G., and Vereecken, H. (2020). "Simulation of spatial variability in crop leaf area index and yield using agroecosystem modeling and geophysics-based quantitative soil information," Vadose Zone J. 19(1), e20009.

Brutsaert, W. (1964). "The propagation of elastic waves in unconsolidated unsaturated granular mediums," J. Geophys. Res. 69, 243-257.

Brutsaert, W. and Luthin, J. N. (1964). "The velocity of sound in soils near the surface as a function of the moisture content," J. Geophys. Res. 69, 643-652. 
Calamita, G., Perrone, A., Brocca, L., Onorati, B., and Manfreda, S. (2015). "Field test of a multifrequency electromagnetic induction sensor for soil moisture monitoring in southern Italy test sites," J. Hydrol. 529, 316-329.

Callegary, J. B., Ferré, T. P. A., and Groom, R. W. (2007). "Vertical Spatial Sensitivity and Exploration Depth of Low-Induction-Number Electromagnetic-Induction Instruments," Vadose Zone J. 6(1), 158.

Callegary, J. B., Ferré, T. P. A., and Groom, R. W. (2012). "Three-Dimensional Sensitivity Distribution and Sample Volume of Low-Induction-Number Electromagnetic-Induction Instruments," Soil Sci. Soc. Am. J. 76(1), 85 .

Cimpoiaşu, M. O., Kuras, O., Pridmore, T., and Mooney, S. J. (2020). "Potential of geo-electrical methods to monitor rootzone processes and structure: A review," Geoderma 365, 114232.

Corwin, D. L. and Lesch, S. M. (2003) "Application of Soil Electrical Conductivity to Precision Agriculture: Theory, Principles, and Guidelines," Agron. J. 95, 455-471.

Corwin, D. L. and Lesch, S. M. (2005). "Apparent soil electrical conductivity measurements in agriculture," Comput. Electron. Agr. 46, 11-43.

Corwin, D. L., Lesch, S. M., Ostler, S. R., and Kakkka, S. R. (2006). "Monitoring managementinduced spatio-temporal changes in soil quality through soil sampling directed by apparent conductivity," Geoderma 131, 369-387.

Corwin, D. L. (2008). "Past, present, and future trends in soil electrical conductivity measurements using geophysical methods," Handbook of Agricultural Geophysics, 17-44.

Corwin, D. L. and Rhoades, J. D. (1984). "Measurement of inverted electrical conductivity profiles using electromagnetic induction," Soil Sci. Soc. Am. J. 48(2), 288-291.

Dahlin, T., Aronsson, P., and Thörnelöf, M. (2014). "Soil resistivity monitoring of an irrigation experiment," Near Surf. Geophys. 12, 35-43.

Doolittle, J. A. and Brevik, E. C. (2014). "The use of electromagnetic induction techniques in soils studies," Geoderma 223-225, 33-45.

Flammer, I., Blum, A., Leiser, A., and Germann, P. (2001). "Acoustic assessment of flow patterns in unsaturated soil," J. Appl. Geophys. 46, 115-128.

Gallipoli, D., Wheeler, S. J., and Karstunen, M. (2003). "Modelling the variation of degree of saturation in a deformable unsaturated soil," Géotechnique 53, 105-112.

Garré, S., Javaux, M., Vanderborght, J., Pagès, L., and Vereecken, H. (2011) "Three-dimensional electrical resistivity tomography to monitor root zone water dynamics", Vadose Zone J., 10, 412424.

Gao, W., Watts, C. W., Ren, T., Shin, H.-C., Taherzadeh, S., Attenborough, K., Jenkins, M., and Whalley, W. R. (2013). "Estimating penetrometer resistance and matric potential from the velocities of shear and compression waves," Soil Sci. Soc. Am. J. 77, 721-728. 
Gray, W. G. and Schrefler, B. A. (2001). "Thermodynamic approach to effective stress in partially saturated porous media," Eur. J. Mech. A/Solids 20, 521-538.

Gregory, A. S., Bird, N. R. A., Whalley, W. R., Matthews, G. P., and Young, I. M. (2010). "Deformation and shrinkage effects on the soil water release characteristic," Soil Sci. Soc. Am. J. 74, 1104-1112.

Hanssens, D., Delefortrie, S., Bobe, C., Hermans, T., and De Smedt, P. (2019). "Improving the reliability of soil EC-mapping: Robust apparent electrical conductivity ( $\mathrm{rECa}$ ) estimation in groundbased frequency domain electromagnetics," Geoderma 337, 1155-1163.

Hayashi, M. (2004). "Temperature-electrical conductivity relation of water for environmental monitoring and geophysical data inversion," Environ. Monit. Assess. 96, 119-128.

Heagy, L. J., Cockett, R., Kang, S., Rosenkjaer, G. K., and Oldenburg, D. W. (2017). "A framework for simulation and inversion in electromagnetics," Comput. Geosci. 107, 1-19.

Huang, J., Pedrera-Parrilla, A., Vanderlinden, K., Taguas, E. V., Gómez, J. A., and Triantafilis, J. (2017). "Potential to map depth-specific soil organic matter content across an olive grove using quasi-2 $\mathrm{d}$ and quasi-3d inversion of DUALEM-21 data," CATENA 152, 207-217.

JafarGandomi, A. and Binley, A. (2013). "A Bayesian trans-dimensional approach for the fusion of multiple geophysical datasets," J. Appl. Geophys. 96, 38-54.

Jennings, J. E. B. and Burland, J. B. (1962). "Limitations to the use of effective stresses in partly saturated soils," Géotechnique 12, 125-144.

Khalili, K. and Khabbaz, M. H. (1998). "A unique relationship for $\chi$ for the determination of the shear strength of unsaturated soils," Géotechnique 48, 681-687.

King, J. A., Dampney, P. M. R., Lark, R. M., Wheeler, H. C., Bradley, R. I., and Mayr, T. R. (2005). "Mapping Potential Crop Management Zones within Fields: Use of Yield-map Series and Patterns of Soil Physical Properties Identified by Electromagnetic Induction Sensing," Precis. Agric. 6(2), 167181.

Koestel, J., Kemna, A., Javaux, M., Binley, A., and Vereecken, H. (2008). "Quantitative imaging of solute transport in an unsaturated and undisturbed soil monolith with 3-D ERT and TDR," Water Resour. Res. 44, W12411.

Korsaeth, A., Riley, H., Kværn $\varnothing$, S. H., and Vestgarden, L. S. (2008). "Relations between a commercial soil survey map based on soil apparent electrical conductivity (ECa) and measured soil properties on a morainic soil in Southeast Norway," in Handbook of Agricultural Geophysics, edited by B. J. Allred, J. J. Daniels, and M. R. Ehsani (CRC Press, Boca Raton), Chap. 13.

Laloy, E., Javaux, M. Vanclooster, M., Roisin, C., and Bielders, C. L. (2011). "Electrical resistivity in a loamy soil Identification of the appropriate pedo-electrical model," Vadose Zone J. 10, 1023-1033.

Lavoué, F., van der Kruk, J., Rings, J., André, F., Moghadas, D., Huisman, J. A., Lambot, S., Weihermüller, L., Vanderborght, J., and Vereecken, H. (2010). "Electromagnetic induction calibration using apparent electrical conductivity modelling based on electrical resistivity tomography," Near Surf. Geophys. 8, 553-561. 
Lo, W.-C. and Sposito, G. (2013). "Acoustic waves in unsaturated soils," Water Resour. Res. 49, 5674-5684.

Lu, Z. (2014). "Feasibility of using a seismic surface wave method to study seasonal and weather effects on shallow surface soils," J. Environ. Eng. Geoph. 19, 71-85.

Lu, Z. and Sabatier, J. M. (2009). "Effects of soil water potential and moisture content on sound speed," Soil Sci. Soc. Am. J. 73, 1614-1625.

Lück, E., Gebbers, R., Ruehlmann, J., and Spangenberg, U. (2009). "Electrical conductivity mapping for precision farming," Near Surf. Geophys. 7, 15-25.

Ma, R., McBratney A., Whelan B., Minasny B. and Short M. (2011). "Comparing Temperature Correction Models for Soil Electrical Conductivity Measurement", Precis. Agric. 12(1), 55-66.

Macleod, C.J.A, Humphreys, M,W., Whalley, W.R., Turner, L., Binley, A., Watts, C.W., Skøt, L., Joynes, A., Hawkins, S., King, I.P., O'Donovan, S., and Haygarth, P. M. (2013), “A novel grass hybrid to reduce flood generation in temperate regions," Sci. Rep. 3, 1683.

Martini, E., Werban, U., Zacharias, S., Pohle, M., Dietrich, P., and Wollschläger, U. (2017). “Repeated electromagnetic induction measurements for mapping soil moisture at the field scale: validation with data from a wireless soil moisture monitoring network," Hydrol. Earth Syst. Sci. 21(1), 495-513.

McLachlan, P., Blanchy, G. and Binley, A. (2021). "EMagPy: open-source standalone software for processing, forward modeling and inversion of electromagnetic induction data," Comput. Geosci. 146, 104561.

McNeill, J. D. (1980a). "Electrical conductivity of soils and rocks," Technical Note TN-5.

McNeill, J. D. (1980b). "Electromagnetic terrain conductivity measurement at low induction numbers," Technical Note TN-6.

Michot, D., Benderitter, Y., Dorigny, A., Nicoullaud, B., King, D., and Tabbagh, A. (2003). "Spatial and temporal monitoring of soil water content with an irrigated corn crop cover using surface electrical resistivity tomography", Water Resour. Res., 39(5), 1138.

Monteiro Santos, F. A. (2004). "1-D laterally constrained inversion of EM34 profiling data," J. Appl. Geophys. 56(2), 123-134.

Moral, F. J. and Serrano, J. M. (2019). "Using low-cost geophysical survey to map soil properties and delineate management zones on grazed permanent pastures," Precis. Agric. 20, 1000-1014.

Nuth, M. and Laloui, L. (2008). "Effective stress concept in unsaturated soils: Clarification and validation of a unified framework," Int. J. Numer. Anal. Met. 32, 771-801.

Paetzold, R. F., Matzkanin, G. A., and Santos, A. D. L. (1985). Surface Soil Water Content Measurement Using Pulsed Nuclear Magnetic Resonance Techniques. Soil Sci. Soc. Am. J. 49(3), 537-540.

Panissod, C., Dabas, M., Hesse, A., Jolivet, A., Tabbagh, J., and Tabbagh, A. (1998). "Recent developments in shallow-depth electrical and electrostatic prospecting using mobile arrays", Geophysics 63(5), 1542-1550. 
Reyes, J., Wendroth, O., Matocha, C., Zhu, J., Ren, W., and Karathanasis, A.D. (2018). "Reliably Mapping Clay Content Coregionalized with Electrical Conductivity," Soil Sci. Soc. Am. J. 82, 578-592.

Rhoades, J. D., Raats, P. A. C., and Prather, R. J. (1976). "Effects of liquid-phase electrical conductivity, water content, and surface conductivity on bulk soil electrical conductivity," Soil Sci. Soc. Am. J. 40, 651-655.

Roy, A. and Apparao, A. (1971). "Depth of investigation in direct current methods," Geophysics 36, 943-959.

Robinson, D. A., Abdu, H., Lebron, I., and Jones, S. B. (2012). "Imaging of hill-slope soil moisture wetting patterns in a semi-arid oak savanna catchment using time-lapse electromagnetic induction," J. Hydrol., 416-417, 39-49.

Rossi, R., Pollice, A., Bitella, G., Labella, R., Bochicchio, R., and Amato, M. (2018). "Modelling the nonlinear relationship between soil resistivity and alfalfa NDVI: A basis for management zone delineation," J. Appl.Geophys. 159, 146-156.

Rücker, C., Günther, T., and Wagner, F. M. (2017). "pyGIMLi: An open-source library for modelling and inversion in geophysics," Comput. Geosci. 109, 106-123.

Samouëlian, A., Cousin, I., Tabbagh, A., Bruand, A., and Richard, G. (2005). "Electrical resistivity survey in soil science: a review," Soil Till. Res. 83(2), 173-193.

Shanahan, P. W., Binley, A., Whalley, W. R., and Watts, C. W. (2015). "The use of electromagnetic induction to monitor changes in soil moisture profiles beneath different wheat genotypes," Soil Sci. Soc. Am. J. 79, 459-466.

Sharma, R. and Gupta, A. (2010). "Continuous wave acoustic method for determination of moisture content in agricultural soil," Comput. Electron. Agr. 73, 105-111.

Sheets, K. R. and Hendrickx, J. M. H. (1995). "Noninvasive Soil Water Content Measurement Using Electromagnetic Induction," Water Resour. Res. 31(10), 2401-2409.

Shin, H.-C., Taherzadeh, S., Attenborough, K., Whalley, W. R., and Watts, C. W. (2013). "Noninvasive characterization of pore-related and elastic properties of soils in linear Biot-Stoll theory using acoustic-to-seismic coupling," Eur. J. Soil. Sci. 64, 308-323.

Shin, H.-C., Watts, C. W., Whalley, W. R., Attenborough, K., and Taherzadeh, S. (2017). "Noninvasive estimation of the depth profile of soil strength with acoustic-to-seismic coupling measurement in the presence of crops," Eur. J. Soil. Sci. 68, 758-768.

Shin, H.-C., Whalley, W. R., Attenborough, K., and Taherzadeh, S. (2016). "On the theory of Brutsaert about elastic wave speeds in unsaturated soils," Soil Till. Res. 156, 155-165.

Slater, L. D. and Lesmes, D. (2002). "IP interpretation in environmental investigations," Geophysics 67(1), 77-88.

Sørensen, K. (1996) “Pulled Array Continuous Electrical Profiling," First Break, 14(3), 85-90. 
Stoll, R. D. (1974). "Acoustic waves in saturated sediments," in Physics of Sound in Marine Sediments, edited by L. Hampton (Plenum Press, New York), pp. 19-39.

Sudduth, K. A., Kitchena, N. R., Wiebold, W. J., Batchelor, W. D., Bollero, G. A., Bullock, D. G., Clay, D. E., Palm, H. L., Pierce, F. G., Schuler, R. T., and Thelen, K. D. (2005). "Relating apparent electrical conductivity to soil properties across the north-central USA," Comput. Electron. Agr. 46, 263-283.

Tooms, S., Taherzadeh, S., and Attenborough, K. (1993). "Sound propagation in a refracting fluid above a layered fluid-saturated porous elastic material," J. Acoust. Soc. Am. 93(1), 173-181.

Triantafilis, J. and Lesch, S. M. (2005). "Mapping clay content variation using electromagnetic induction techniques," Comput. Electron. in Agr. 46(1-3), 203-237.

von Hebel, C., Rudolph, S., Mester, A., Huisman, J. A., Kumbhar, P., Vereecken, H., and van der Kruk, J. (2014). "Three-dimensional imaging of subsurface structural patterns using quantitative large-scale multiconfiguration electromagnetic induction data," Water Resour. Res. 50(3), 2732-2748.

von Hebel, C., van der Kruk, J., Huisman, J. A., Mester, A., Altdorff, D., Endres, A. L., Zimmermann, E., Garré, S., and Vereecken, H. (2019). "Calibration, Conversion, and Quantitative Multi-Layer Inversion of Multi-Coil Rigid-Boom Electromagnetic Induction Data," Sensors 19(21), 4753.

Wait, J. R. (1982). Geo-electromagnetism, New York: Academic Press.

Waxman, M. H. and Smits, L. J. M. (1968). "Electrical conductivities in oil-bearing shaly sands," Soc. Petrol Eng. J. 8, 107.

Weller, A., Slater, L., Binley, A., Nordsiek, S., Xu, S. (2015). "Permeability prediction based on induced polarization: insights from measurements on sandstone and unconsolidated samples spanning a wide permeability range," Geophysics 80(2), D161-D173

Whalley, W. R., Binley, A., Watts, C. W., Shanahan, P., Dodd, I. C., Ober, E. S., Ashton, R. W., Webster, C. P., White, R. P., and Hawkesford, M. J. (2017). "Methods to estimate changes in soil water for phenotyping root activity in the field," Plant Soil 415, 407-422.

Whalley, W. R., Jenkins, M., and Attenborough, K. (2011). "The velocity of shear waves in saturated soil," Soil Sci. Soc. Am. J. 75, 1652-1657.

Whalley, W. R., Jenkins, M., and Attenborough, K. (2012). "The velocity of shear waves in unsaturated soil," Soil Till. Res. 125, 30-37.

Zhu, Q., Lin, H. S., and Doolittle, J. A. (2013). "Functional soil mapping for site specific soil moisture and crop yield management," Geoderma 200-201, 45-54. 